\title{
Laboratory Work in Support of West Valley Glass Development
}

L. R. Bunnell

May 1988

Prepared for the U.S. Department of Energy under Contract DE-AC06-76RLO 1830

Pacific Northwest Laboratory Operated for the U.S. Department of Energy by Battelle Memorial Institute 


\title{
DISCLAIMER
}

This report was prepared as an account of work sponsored by an agency of the United States Government. Neither the United States Covernment nor any agency thereof, nor Battelie Memorial Institute, nor any or their employees, makes any warranty, expressed or implied, or assumes any legal liability or responsibility for the accuracy, completeness, or usefulness of any information, apparatus, product, or process disclosed, or represents that its use would not infringe privately owned rights. Reference herein to any specific commercial product, process, or service by trade name, trademark, manufacturer, or otherwise does not necessarily constitute or imply its endorsement, recommendation, or favoring by the United States Government or any agency thereof, or Battelfe Memorial institute. The views and opinions of authors expressed herein do not necessarily state or reflect those of the United States Government or any agency thereof, or Battelle Memorial Institute.

\author{
PACIFIC NORTHWEST LABORATORY \\ operated by \\ BATTELLE MEMORIAL INSTITUTE \\ for the \\ UNITED STATES DEPARTMENT OF ENERGY \\ under Contract DE-ACO6-76RLO 1830
}

\begin{tabular}{|c|c|}
\hline Printed in the & of America \\
\hline National Tech & tion Service \\
\hline United States & f Commerce \\
\hline $\begin{array}{r}5285 \\
\text { Spring }\end{array}$ & \\
\hline & \\
\hline & \\
\hline Pages & $\begin{array}{l}\text { Price } \\
\text { Codes }\end{array}$ \\
\hline $001-025$ & $\mathrm{~A} 02$ \\
\hline $026-050$ & $\mathrm{~A} 03$ \\
\hline $051-075$ & A04 \\
\hline $076-100$ & A05 \\
\hline $101-125$ & $\mathrm{AOS}$ \\
\hline $126-150$ & $\mathrm{~A} 07$ \\
\hline $7 \$ 1-175$ & $\mathrm{AOA}$ \\
\hline $176-200$ & A09 \\
\hline $201-225$ & $\mathrm{~A} 010$ \\
\hline $226-250$ & A011 \\
\hline $251-275$ & A012 \\
\hline $276-300$ & $A 013$ \\
\hline
\end{tabular}


L. R. Bunneil

May 1988

Prepared for the U.S. Department of Energy under Contract DE-AC06-76RLO 1830

Pacific Northwest Laboratory Richland, Washington 99352 


\section{SUMMARY}

Over the past six years, Pacific Northwest Laboratory (PNL) has conducted several studies in support of waste glass composition development and testing of glass compositions suitable for immobilizing the nuclear wastes stored at West Valley, New York. As a result of pilot-scale testing conducted by PNL, the glass composition was changed from that originally recommended in response to changes in the waste stream, and several processing-related problens were discovered. These problems were solved, or sufficiently addressed to determine their likely effect on the glass melting operations to be conducted at West Valley. This report describes the development of the waste glass composition, WV-205, and discusses solutions to processing problems such as foaming and insoluble sludges, as well as other issues such as effects of feed variations on processing of the resulting glass. An evaluation of the WV-205 glass from a repository perspective is included in the appendix to this report. 
.

.

เ 


\section{ACKNOWLEDGMENTS}

The author of this report functioned mainly as a compiler of reports on glass studies performed by others. L. A. Chick performed the statistically designed mixture studies that led to the present West valley glass composition. Most of the work on foaming, redox control, and phase separation was done by D. S. Goldman. M. A. Reimus performed the variability study, while the leaching performance evaluation was done by D. M. Strachan. The computer codes PREDICT and BATCHER were written by C. A. LoPresti. The high quality of the original work and the help given to the author in terms of source material is acknowledged. 
. 


\section{CONTENTS}

SUMMARY

ACKNOWLEDGMENTS

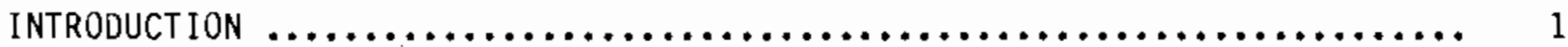

STATISTICALLY DESIGNED MIXTURE STUDY $\ldots \ldots \ldots \ldots \ldots \ldots \ldots \ldots \ldots \ldots \ldots \ldots \ldots \ldots$

EVOLUTION OF THE WV-205 COMPOSITION $\ldots \ldots \ldots \ldots \ldots \ldots \ldots \ldots \ldots \ldots \ldots \ldots \ldots$

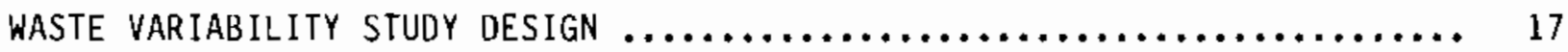

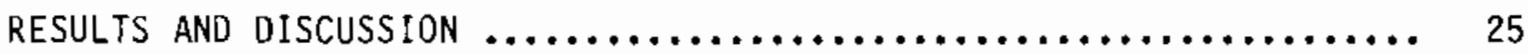

Melting Rates $\ldots \ldots \ldots \ldots \ldots \ldots \ldots \ldots \ldots \ldots \ldots \ldots \ldots \ldots \ldots \ldots \ldots$

Secondary Phases $\ldots \ldots \ldots \ldots \ldots \ldots \ldots \ldots \ldots \ldots \ldots \ldots \ldots \ldots \ldots \ldots \ldots$

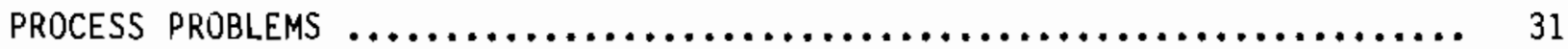

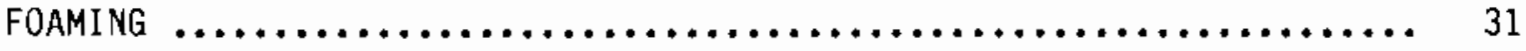

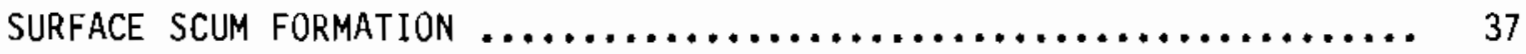

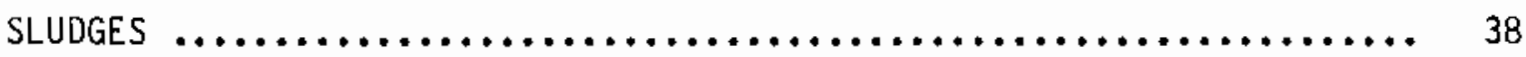

PROCESS CONTROLS $\ldots \ldots \ldots \ldots \ldots \ldots \ldots \ldots \ldots \ldots \ldots \ldots \ldots \ldots \ldots \ldots \ldots \ldots \ldots \ldots \ldots$

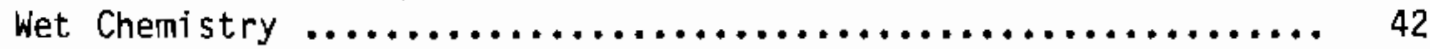

Colorimetry $\ldots \ldots \ldots \ldots \ldots \ldots \ldots \ldots \ldots \ldots \ldots \ldots \ldots \ldots \ldots \ldots \ldots \ldots \ldots$

Mossbauer Spectroscopy $\ldots \ldots \ldots \ldots \ldots \ldots \ldots \ldots \ldots \ldots \ldots \ldots \ldots \ldots \ldots$

Ion Chromatography $\ldots \ldots \ldots \ldots \ldots \ldots \ldots \ldots \ldots \ldots \ldots \ldots \ldots \ldots \ldots$

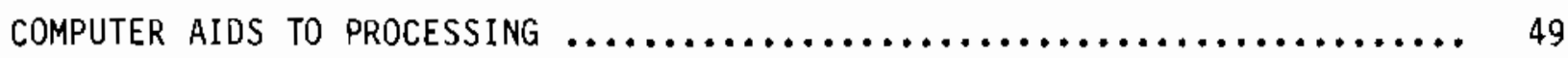

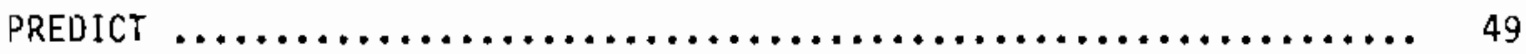

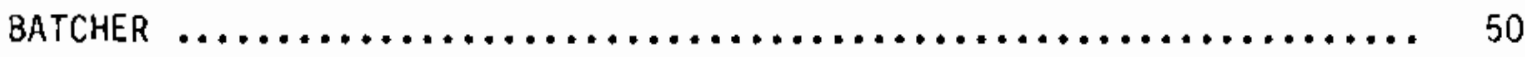

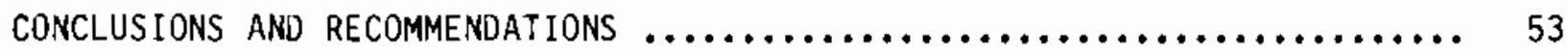

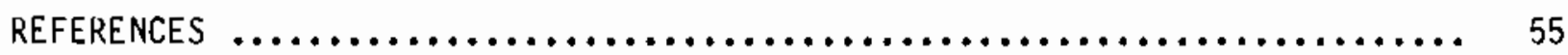

APPENDIX - LEACH TESTING AND EVALUATION OF WV-205 GLASS FROM

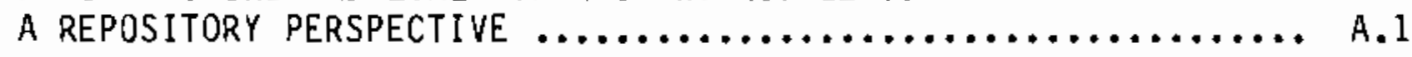




\section{FIGURES}

1 Melting Rate of Partially or Fully Nitrated Melter

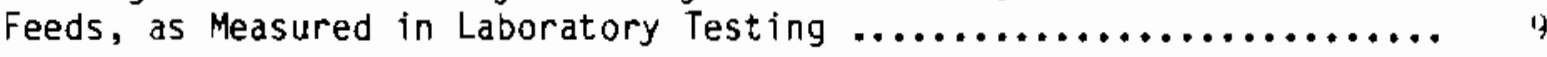

2 Comparison of Melting Rates Measured in ECM and Laboratory Crucible Tests, Showing Reasonably Linear Correlation ............. 1:

3 Feed Melting Rate Measured in the ECM, as a Function of Total Concentration of Boron and Alkali Dxides in the Feed ............. 1:3

4 Laboratory Melting Rates Measured for Sugared and Non-Sugared Versions of the WV-205 Composition $\ldots \ldots \ldots \ldots \ldots \ldots \ldots \ldots$

5 The Logic Process Used to Design the Waste Variability Study ........ 18

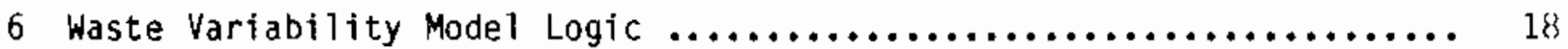

7 Melting Rates for Several Composition Variations $\ldots \ldots \ldots \ldots \ldots \ldots \ldots \ldots$ ?

8 Apparatus Used to Measure Reboil Pressures of Molten Glasses for Studying Foaming................................. 32

9 Reboil Pressures of a Variety of Waste Glasses, Correlated with Their Tendency to Foam During Actual Melting ................ 3 :

10 Chronological Record of Melting Behavior Observed During PSCM-19, Showing the Effect of Sugar Additions on Melting Rate............. 34

11 Spectral Purity, as Measured on West Valley Glass Powders, Compared to the Ferrous/Ferric Iron Ratio 


\section{TABLES}

1 Compositions of Glass WV-182 and WV-183 $\ldots \ldots \ldots \ldots \ldots \ldots \ldots \ldots \ldots, 7$

2 West Valley Glass Formulations Used in FY85 Testing ............... 10

3 Model Factors Used to Account for Potential Feed

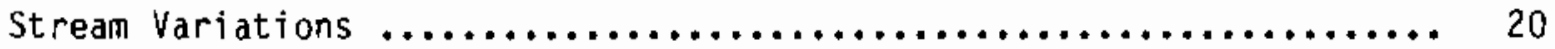

4 Ranges of Individual Oxides Based on SVS Results $\ldots \ldots \ldots \ldots \ldots \ldots . . . \ldots 22$

5 Experimental Variability Test Matrix ......................... 23

6 Compositions Used in the Variability Study and Predicted

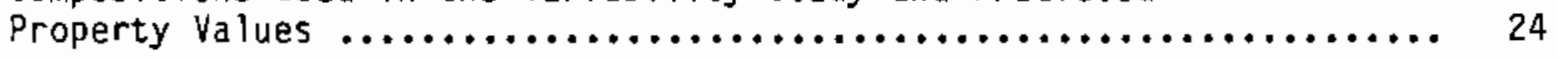

7 Melting Rates and Cold Cap Burn-Off Times $\ldots \ldots \ldots \ldots \ldots \ldots \ldots \ldots \ldots, 26$

8 Wet-Chemistry Analysis Results for Hest Valley Glass Ferrous/Ferric Iron Ratios Showing Negligible Atmosphere Effect over Four Runs 
1 


\section{INTRODUCTION}

At the beginning of the West Valley Demonstration Project in FY 1982 , borosilicate glass had been chosen as the waste form for U.S. efforts to immobilize high-level radioactive nuclear waste. The nuclear waste at West Valley (WV) originated from a commercial reprocessing operation and thus differed significantly from the Defense Program-originated wastes that are stored at Savannah River, South Carolina, and Hanford, Washington, for which borosilicate glass compositions had been extensively studied.

The most significant differences between the West Valley commercial wastes and Savannah River-Hanford defense wastes are that the West Valley wastes contain larger anounts of iron, dissolved during the chemical processing, and higher amounts of aluminum and phosphorus than are typically found in defense high-level waste. With these differences, it might have been a mistake to incorporate the West Valley waste into some generic borosilicate nuclear waste glass without proper glass design and evaluation.

From 1982 to 1983, a glass composition was developed at Pacific Northwest Laboratory $(P N L)^{(a)}$ specifically for the West Valley wastes. A great deal of testing and evaluation of this glass (glass WV-182) was done to assure that it could be processed in present nuclear waste glass melting equipment and that the resulting glass would meet present applicable requirements in terms of its durability. As pilot-scale runs to assure processability of the glass feed were being performed in PNL's pilot-scale ceramic melter (PSCM), several problems were revealed and a significant amount of laboratory-scale support was supplied to assist in this debugging phase.

The purpose of this report is to describe all of the efforts that went into determining a final recomended glass composition in sufficient detail to be useful to those not directly involved at the time. The report can then serve as part of the technology transfer which must now occur for this information to be used.

(a) Operated for the U.S. Department of Energy by Battelle Memorial Institute under Contract DE-AC06-76RLO 1830. 



\section{STATISTICALLY DESIGNED MIXTURE STUDY}

The many mixture studies that have been performed can be classified into two types. One type is the thorough and scientific study of a highly idealized glass, which usually contains three, or at most four, components. These idealized glass studies usually involve measuring changes in several critical properties of the glass as a function of composition. Such studies do contribute to the fundamental understanding of glasses. However, they contribute little to the knowledge of real-world glasses with more components, and are virtualiy useless for the design of nuclear waste glasses which contain dozens of components.

Another type of glass study that has been performed is the empirical mixture study of real-world glass types. In these studies, the glass compositions are changed and the glasses are tested for the consequences of the changes. Compositions are fairly complex but still much simpler than nuclear waste glasses. Interactions are often not thoroughly tested from a statistical standpoint. This results in the assumption of several "rules" for describing the results of composition changes. These rules are valid enough within the composition field studied but can be difficult to apply to other compositions, particularly the complex compositions found in nuclear waste glass. Thus, there is little predictive power as a result of such studies.

At PNL, a third type of study was used which applied statistical methods to the design and testing of model nuclear waste glasses of realistic complexity. The goals of the study were to 1) statistically model the effect of composition changes on the physical properties of a glass to obtain real predictive power within the composition field studied, 2) build a data base of composition changes and effects, and 3) eventually, design a durable and processable glass composition. The techniques and results of the mixture study are described in detail in a summary report (Chick et al. 1984).

The mixture study assessed the effects of seven oxjde components on glass properties. The choice of the seven components involved decisions about, for instance, which alkali or alkaline-earth oxide flux would best represent the group of possible fluxes. One of the seven components was itself a mixture of 
thirteen oxides in fixed proportion. This mixture represented part of the West Valley waste composition. Over 100 melts, combining the seven components into a wide variety of statistically chosen compositions, were tested. Critical processing or performance parameters such as viscosity, electrical conductivity, thermal expansion, crystallinity, and chemical durability were measured and empirically modelled as a function of the glass composition.

Mathematical models, such as the PREDICT program discussed in a later section of this report, were then used to predict the optimum formulation. This optimum glass (WV-182) was tested and adjusted to arrive at the final composition recommended for use at West Valley. Later waste-stream changes and corrections of processing difficulties resulted in further changes to the recommended composition, but the mathematical models were invaluable in decreasing the time necessary to design glasses to respond to these changes. Any future changes that are necessary can be checked via the models to provide assurance that resulting property changes will be acceptable. One exception to this is the lack of lithium oxide in the glasses used for the data base, which indicates caution should be used with present Li-containing compositions.

As an example of the use of these models, consider the final round of glass development, conducted to accommodate waste stream changes and increase the processing rate. Twenty-three glasses were evaluated; all of these were chosen with the aid of the models before ever being melted, which was very helpful when quick response was critical. In the final analysis, glass WV-205 was chosen over the other candidate glasses on the basis of demonstrated chemical durability and performance in the melter. WV-205 differs enough from the other candidates that, without the modeling, much more testing would have been required before making such a crucial recommendation. Several important physical properties have yet to be measured for this glass, a situation which should be corrected.

The mathematical model developed during the statistically designed mixture study appears to be a good predictor of glass properties over the composition space it covers. This model is thus applicable to the borosilicate glasses that are required to dissolve waste streams similar to the West Valley waste stream composition and which will be processed in a joule-heated electric 
melter. Perhaps more importantly, the computer model-aided statistical design approach is on a sounder footing than most mixture studies done in the past, and should be an efficient way to optimize or qualify the design of any future waste glass. 

- 


\section{EVOLUTION OF THE WV-205 COMPOSITION}

At the end of the statistically designed mixture study, conducted at PNL, it was possible to recommend a glass composition for melter trials with the West Valley waste stream. The composition of this glass, WV-182, is shown in Table I. Glass WV-182 was developed in the laboratory, and had never been melted in a large slurry-fed ceramic melter under realistic conditions.

The first realistic melter trial of glass WV-182 was in the PSCM-19 test. The processing rate was unsatisfactory due to an immiscible calcium phosphate phase that penetrated the cold-cap, (a) coated residual silica grains and formed a chemical insulation that inhibited melting. This sort of difficulty could not have been predicted by the laboratory studies performed in crucibles but certainly emerged during continuously fed pilot-scale melter testing. To eliminate this problem, the calcium content was reduced. Melt viscosity was maintained by increasing the boron content. This resulted in the WV-183 glass composition, also shown in Table 1. To address these and similar problems, melting rate measurements by laboratory tests began during this period. The test used was the so-called crucible test described in the section of this report covering the waste variability study.

TABLE 1. Compositions of G1ass WV-182 and WV-183

Target Chemicals, wt\%

$\begin{array}{ccccccccccc}\frac{\mathrm{Glass}}{2} & \frac{\mathrm{SiO}_{2}}{182} & \frac{\mathrm{B}_{2} \mathrm{O}_{3}}{44.5} & \frac{\mathrm{Na}_{2} \mathrm{O}}{12.7} & \frac{\mathrm{Li}_{2} \mathrm{O}}{15.0} & -- & \frac{\mathrm{CaO}}{3.0} & \frac{\mathrm{Cr}_{2} \mathrm{O}_{3}}{0.7} & \frac{\mathrm{RE}_{2} \mathrm{O}_{3}}{3.2} & \frac{\mathrm{P}_{2} \mathrm{O}_{5}}{2.7} & \frac{\text { Notes }}{\mathrm{PSCM}-19 \text {, high } \mathrm{B},} \\ 183 & 44.6 & 15.5 & 14.7 & -- & 0.7 & 0.7 & 2.0 & 2.6 & \begin{array}{c}\text { ECM, Minimum Ca, pro- } \\ \text { duced RE phosphate } \\ \text { scum }\end{array}\end{array}$

(a) "Cold cap" is a term used to describe the layer of nonfused ingredients that forms on top of molten glass when these ingredients are transported to the melter by water. This cold-cap zone remains but ingredients pass through it continuously as they fuse into glass and are replaced by new material. 
The WV-183 glass was tested in the experimental ceramic melter (ECM) under both oxidizing and reducing conditions by varying the amount of sugar, a common reductant, added to the feed stream. Melting improved with greater sugar additions, which verified laboratory results. However, a viscous surface scum that was difficult to remelt formed after the ECM test. The scum was found to be enriched in angular rare-earth phosphate crystals, which increased the apparent viscosity and retarded melting. As a remedy, the rare-earth concentration was reduced to that expected in the actual waste while zirconia was again used to substitute for uranium and thorium, as had been done with the initial working glass run in PSCM-16 [based on the early Savannah River Laboratory (SRL) glass composition, SRL-131]. The result was WV-192, which processed acceptably in the ECM and left a surface free of phosphate scums.

A re-analysis of the waste at West Valley resulted in the reduction of the chromium concentration by a factor of three, with expectations of fewer $\mathrm{Fe}-\mathrm{Cr}$ crystalline phases in the glass. The best composition in respect to processing parameters and leaching performance of those designed to accommodate this change was WV-199.

From that point, several important changes in the direction of the program occurred. First, concern for $\mathrm{NO}_{\mathrm{x}}$ enissions by the state of New York emphasized the need to reduce the nitrate content in the feed, by changes in the waste processing and by replacement of nitrate glass-forming chemicals with hydroxides. These changes would have the added advantage of lowering the concentration of reducing agents needed to achieve sufficient reducing potential to eliminate melt foaming. (a) However, subsequent laboratory work, as shown in Figure 1, suggested that the melting rate was lower in partially nitrated than in fully nitrated feeds.

Second, interest was growing in following Savannah River technology to use feeds made with formic acid instead of nitric acid, which aiso would address the $\mathrm{NO}_{x}$ emission problem. The related issues included the improved rheological behavior if this option was selected.

(a) A more complete explanation of melt foaming causes and remedies appears later in this report. 


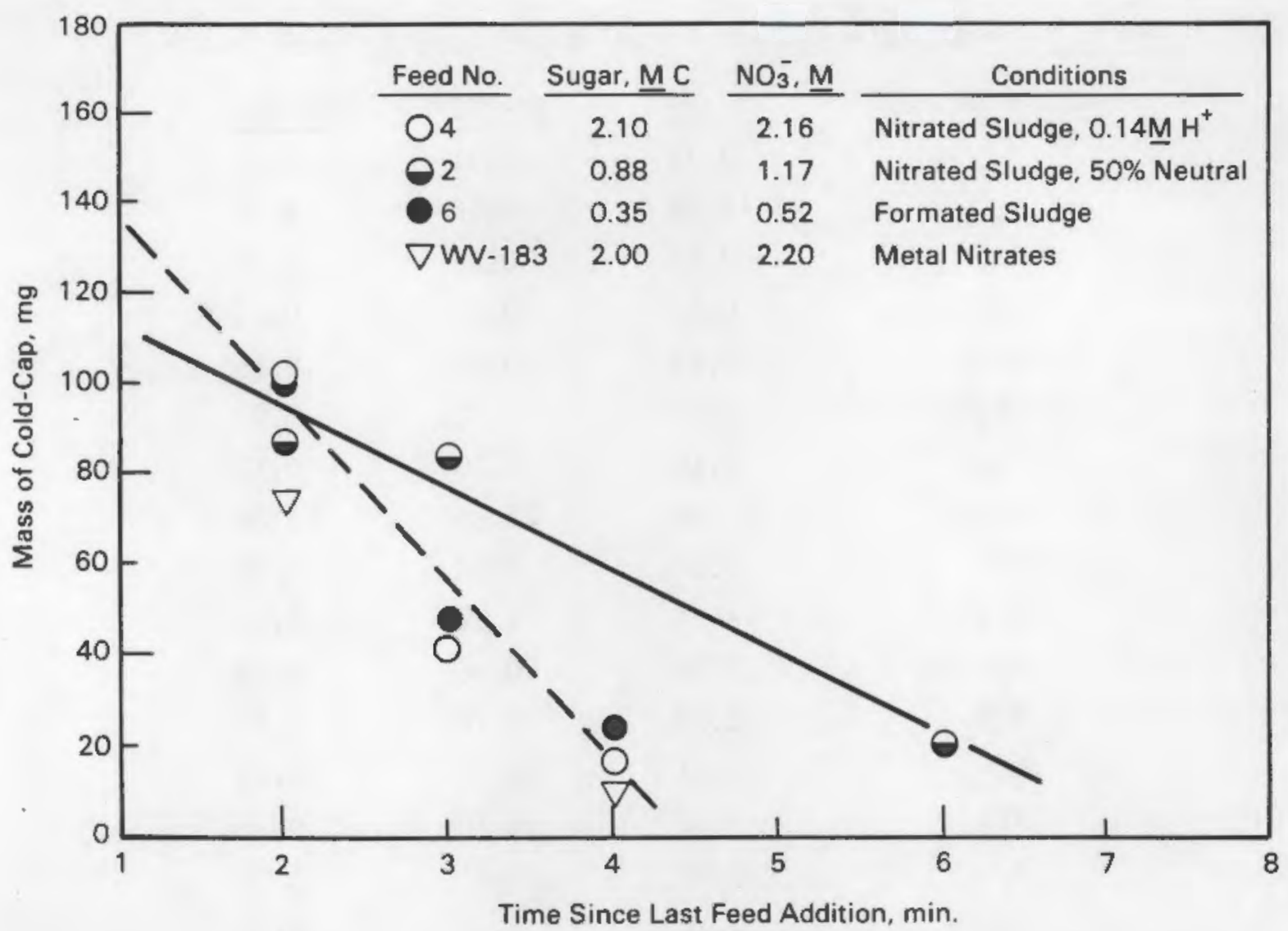

FIGURE 1. Melting Rate of Partially or Fully Nitrated Melter Feeds, as Measured in Laboratory Testing

Third, preliminary leaching data suggested that the WV-199 glass had a poorer chemical durability, by perhaps a factor of three, than SRL-165 glass, the highest-performance nuclear waste glass at the time. This result suggested that lithium, which had been absent since the initial working glass, should be added to the West Valley glass for durability comparable to the SRL-165 glass.

Fourth, although not strictly a technical problem, there was a strong feeling that the final West Valley glass should be as close as possible in composition to the SRL glass in hopes of using much of the extensive data base at SRL.

As inferred in the above discussion, it became clear that the phosphate in the West Valley waste posed a major problem not encountered at Savannah River. As a result of these related problems, a series of glasses from WV-19g 
TABLE 2. West Valley Glass Formulations Used in FY85 Testing

\begin{tabular}{|c|c|c|c|}
\hline Glass 0xides & WV-199 & WV-202 & WV -203 \\
\hline $\mathrm{Al}_{2} \mathrm{O}_{3}$ & 3.31 & 3.31 & 3.31 \\
\hline $\mathrm{B}_{2} \mathrm{O}_{3}$ & 15.56 & 7.56 & 8.80 \\
\hline $\mathrm{BaO}$ & 0.06 & 0.06 & 0.06 \\
\hline $\mathrm{CaO}$ & 0.61 & 0.61 & 0.61 \\
\hline $\mathrm{CeO}_{2}$ & 0.16 & 0.16 & 0.16 \\
\hline $\mathrm{Cr}_{2} \mathrm{O}_{3}$ & 0.22 & 0.22 & 0.22 \\
\hline $\mathrm{Cs}_{2} \mathrm{O}$ & 0.10 & 0.10 & 0.10 \\
\hline $\mathrm{Fe}_{2} \mathrm{O}_{3}$ & 11.84 & 11.84 & 11.84 \\
\hline $\mathrm{K}_{2} \mathrm{O}$ & 0.07 & 0.07 & 0.50 \\
\hline $\mathrm{Li}_{2} \mathrm{O}$ & -- & 4.55 & 3.75 \\
\hline $\mathrm{MgO}$ & 0.16 & 0.16 & 1.30 \\
\hline $\mathrm{MnO}_{2}$ & 1.73 & 1.73 & 1.73 \\
\hline $\mathrm{Na}_{2} \mathrm{O}$ & 14.23 & 10.22 & 14.65 \\
\hline $\mathrm{NiO}$ & 0.70 & 0.70 & 0.70 \\
\hline $\mathrm{P}_{2} \mathrm{O}_{5}$ & 2.52 & 2.52 & 2.52 \\
\hline $\mathrm{RE}_{2} \mathrm{O}_{3}$ & 0.12 & 0.12 & 0.12 \\
\hline $\mathrm{RuO}_{2}$ & 0.08 & 0.08 & 0.08 \\
\hline $\mathrm{SiO}_{2}$ & 45.22 & 52.68 & 45.64 \\
\hline $\mathrm{SO}_{3}$ & 0.50 & 0.50 & 0.50 \\
\hline Sro & 0.03 & 0.03 & 0.03 \\
\hline $\mathrm{TiO}_{2}$ & -- & -- & 0.60 \\
\hline$Y_{2} \mathrm{O}_{3}$ & 0.02 & 0.02 & 0.02 \\
\hline $\mathrm{ZrO}_{2}$ & 3.12 & 3.12 & 3.12 \\
\hline Other & -- & - & $\cdots$ \\
\hline Total & 100.36 & 100.00 & 100.00 \\
\hline
\end{tabular}

to WV-203 was formulated (Table 2) with variable lithium, boron, and sodium to evaluate the resulting chemical durability. WV-202 was designed to simulate SRL-165 glass, but with West Valley waste. WV-203 was designed to simulate the earlier SRL-131S glass (used in PSCM-16), again with the newly defined West Valley waste. 
In the interim, several ECM tests and the PSCM-20 test were run with a nonradioactive formulation designed to contain a significant $\mathrm{Cs}$ and $\mathrm{Sr}$ loading, for the Federal Republic of Germany (FRG). The important result of these tests relative to the West Valley task was that the same melting rate was achieved with and without the presence of the IE-96 zeolite. This supported the growing feeling at the time that zeolite was not a major cause of the melting problems.

Problems were encountered in preparing a feed for WV-200. Its high-boron and low-sodium contents required the use of boric acid and the elimination of sodium oxalate. The boric acid tended to cause feed segregation and some crystallization, whereas the elimination of the sodium oxalate required a significant increase in sugar concentration to impart reducing conditions to the resulting glass, in order to prevent melt foaming. This glass was discarded, except for the purpose of leaching comparisons.

The leaching results revealed similar values of boron release from 28-day $M C C-3^{(a)}$ tests for the SRL-165 glass and its West Valley analog, WV-202. Boron release is used as an indicator of general glass network dissolution, because boron is a network former and is of high solubility in water, so precipitation does not occur. The WV-199, WV-200, and WV-201 glasses had boron releases about a factor of three greater than $W V-202$, and $W V-203$ (SRL-131S analog) had a value nearly ten times that of WV-202.

It is important to note that, in spite of their different waste compositions, WV-202 and SRL-165 have the same glass formers and also the same chemical durability in this test. This suggests that (in this case at least) the durability is largely controlled by the formulations of added glass-forming oxides, with minimal effects due to the West Valley waste.

The melting rates for several West Valley glass compositions, determined from ECM and laboratory crucible tests of the same feeds (see Figure 2), showed a reasonably linear correlation between the two tests. The " $N$ " and " $n$ "

(a) MCC is the Materials Characterization Center at PNL, an entity charged with developing standardized test methods and materials pertinent to nuclear waste forms. 


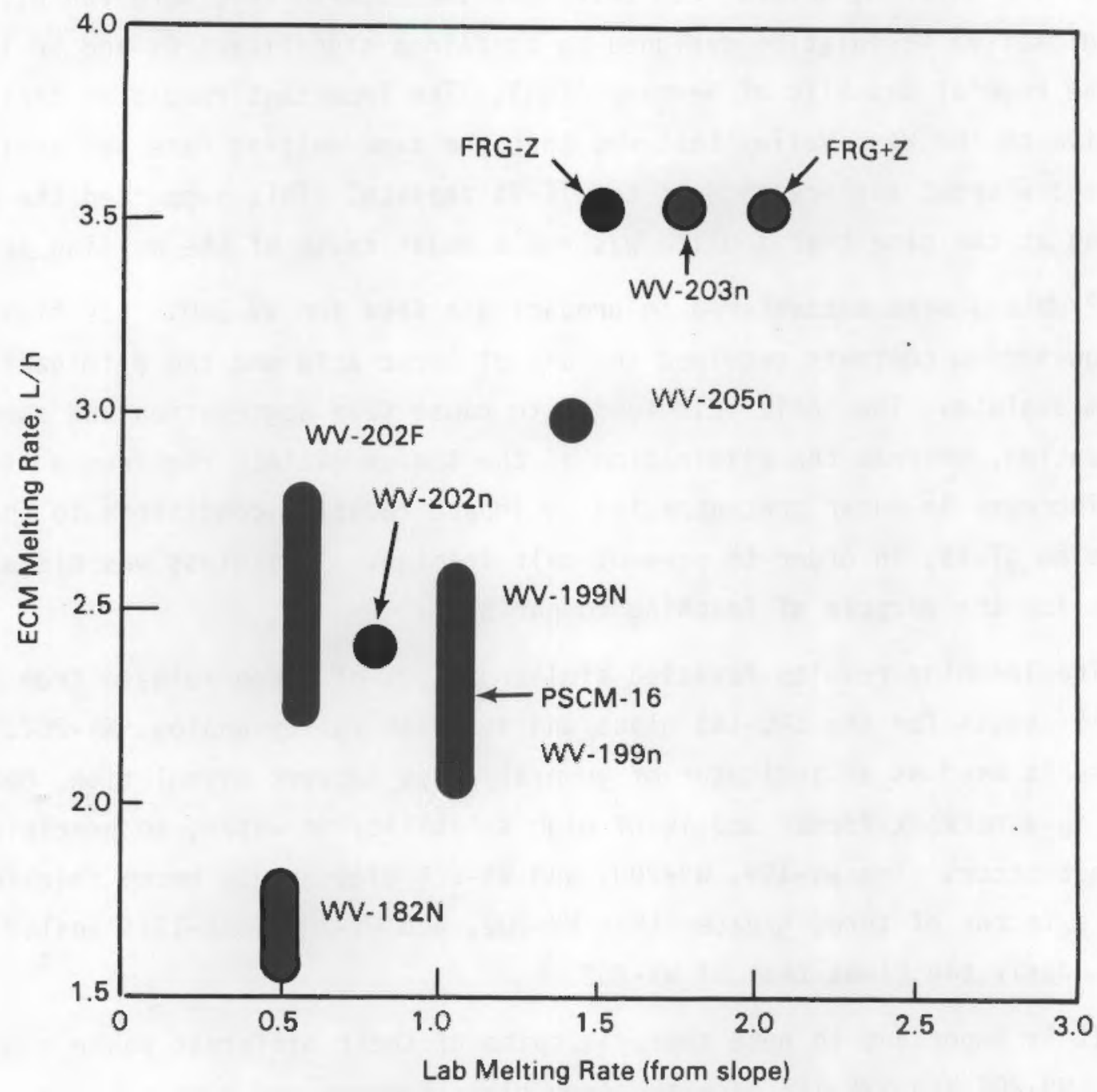

FIGURE 2. Comparison of Melting Rates Measured in ECM and Laboratory Crucible Tests, Showing Reasonably Linear Correlation

suffixes denote feeds that are fully and partially nitrated, respectively. The "F" suffix refers to a fully formated feed. The $F R G+Z$ and $-Z$ denote feeds with and without IE-96 zeolite, respectively. The slopes of the melting rate data from the laboratory crucible tests (see Figure 3 ) were ratioed against the data determined for PSCM-16 feed (actual slope of -20 ), which was assigned a value of unity for the purposes of this figure. The results show that similar melting rates were obtained for WV-202, whether formated or nitrated. 


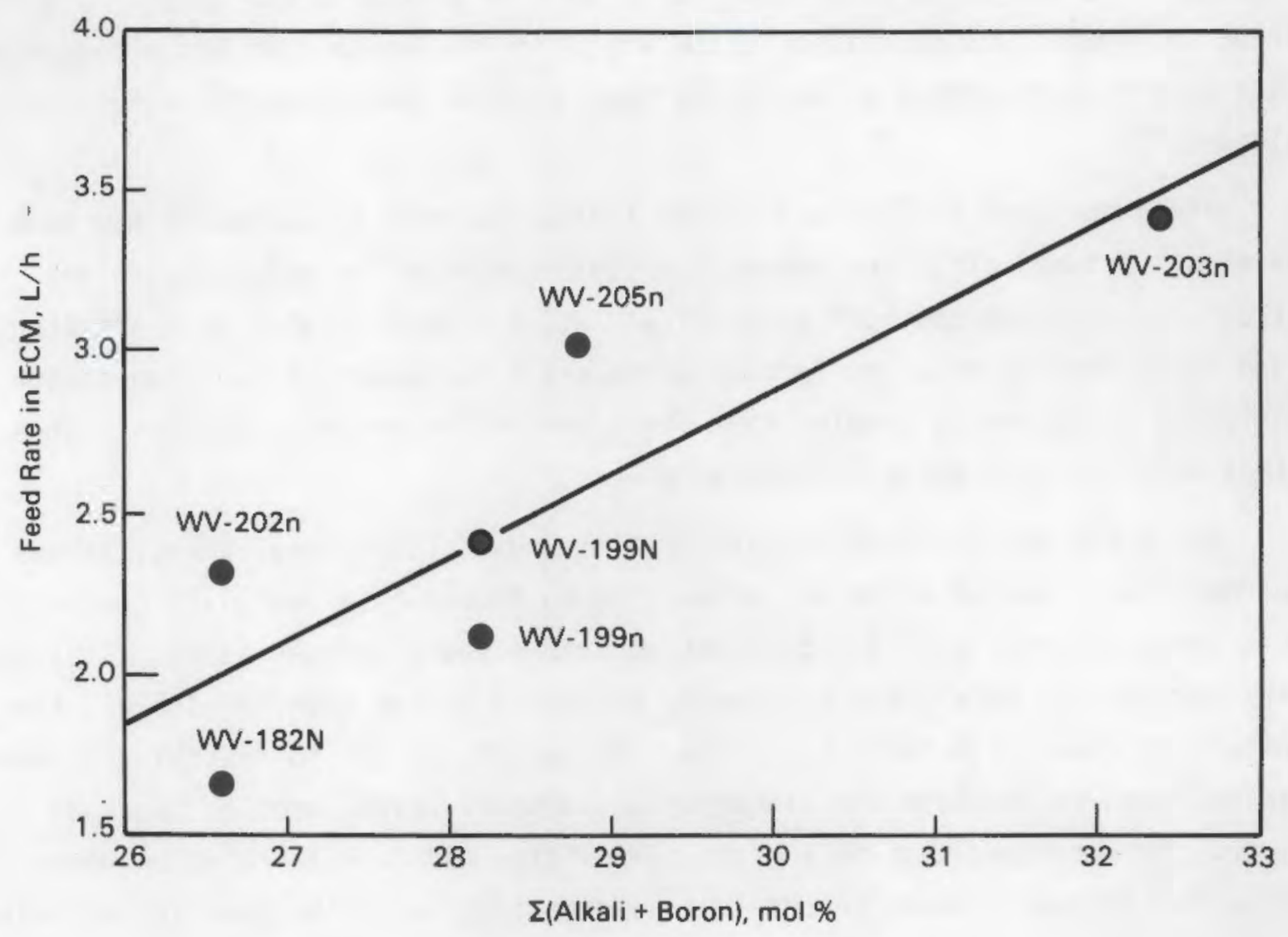

FIGURE 3. Feed Melting Rate Measured in the ECM, as a Function of Total Concentration of Boron and Alkali Oxides in the Feed

Although the laboratory test did not indicate a significant difference, the ECM tests of WV-199 showed a slightly greater melting rate for the fully nitrated formulation. Due to the interest in minimizing $\mathrm{NO}_{x}$ emissions as stated above, the results for WV-199 and WV-199n led to subsequent testing of partially nitrated feeds. The partially nitrated WV-203 formula exhibited the nighest melting rate of the West Valley series tested.

Figure 3 shows a positive correlation between the melting feed rate measured in the ECM and the total concentration of boron and alkali oxides in the various partially and fully nitrated feed formulations. The total concentration of these oxides is not a true mole percent, but rather it is referenced to the weight percent of sodium. Hence, the weight percents of the oxides of lithium, boron, and potassium were multiplied by $2.07,0.89$, and 0.66 , 
respectively, and added to the weight percent of sodium in the glass. The trend in Figure 3 is amplified by the WV-203 glass, which also has a temperature at which its viscosity is $100 \mathrm{P}$, nearly $100^{\circ} \mathrm{C}$ lower than the other glasses. (a)

The importance of Figure 3 is the indication that a compromise may have to be struck between efficient processing (obtained with low-viscosity, highalkali glasses) and chemical durability. While a general view of glass structure would seem to make the foregoing statement redundant, glass composition design is sufficiently complex that the truth of old generalizations is sometimes only apparent after considerable work.

While PNL was involved in this final round of glass development, it was learned that Savannah River was attempting to formulate a new glass composition to accommodate nearly $4 \% \mathrm{~K}_{2} 0$ originating from a newly defined waste. Preliminary versions of this glass reportedly processed better than SRL-165 and had comparable chemical durability. This information led PNL to test WV-205, which was designed to simulate the "interim" glass under development at Savannah River. It was hoped that this glass composition and feed formulation would solve the dilemina between processing and durability with the West Valley waste, as described above.

As shown in Figure 3, the processing rate of WV-205 in the ECM was intermediate between that of WV-203 and the other compositions. Subsequent leach testing revealed a release rate comparable to WV-202 and SRL-165. These positive results led to the testing of partially nitrated WV-205 in the June 1985 PSCM-21 melter test.

The results of the PSCM-21 experiment showed a reasonable melting rate of about $35 \mathrm{~L} / \mathrm{h}$ with $35 \mathrm{~g} / \mathrm{L}$ of sugar in the partially nitrated feed. Midway through the test, sugar additions to the feed were stopped, and the melting rate improved significantly, to nearly $60 \mathrm{~L} / \mathrm{h}$. The effect of sugar on the

(a) The "100-poise point" has processing significance in that this viscosity level is associated with good mixing and processing but slow attack on melter refractories. Any given glass has a viscosity of 100 poise at some temperature and this temperature is determined by actual viscosity measurements. 
melting rate had not previously been tested in the laboratory and so this result was not expected. A subsequent laboratory evaluation of the two PSCM feeds clearly showed the improvement in melting rate after excluding sugar from the feed, as shown in Figure 4. Although some melt foaming was observed in PSCM-21, it was not judged to be severe.

The surface layers sampled from PSCM-21 during feeding of both sugared and non-sugared feed were closely examined by optical and scanning electron microscopy (SEM), in the hope of identifying the mechanism by which the sugar

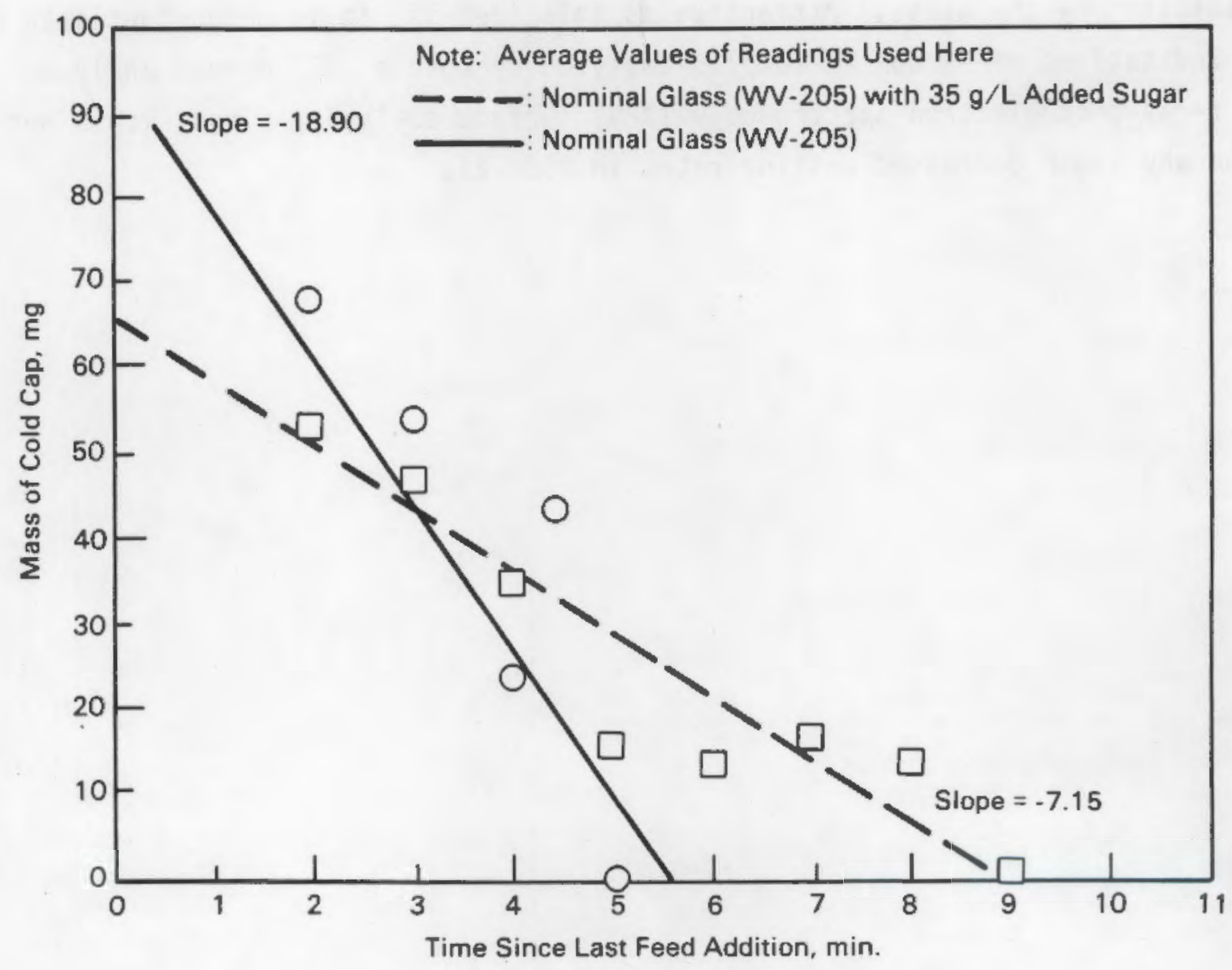

FIGURE 4. Laboratory Melting Rates Measured for Sugared and Non-Sugared Versions of the WV-205 Composition 
had retarded the melting rate. Comparisons of the samples as observed by SEM revealed no obvious differences; in both cases crystalline phases including zircon $\left(\mathrm{ZrSiO}_{4}\right)$, unmelted silica, calcium phosphate, and spinels were present. The volume fractions of these phases were apparently low enough to not cause significant difficulty.

Optical metallography showed, however, that the crystals were bonded into a consolidated mass in the sugared feed, and little glass was present in this mass. One possible explanation was that sugar decomposition left residual carbon, which would act as an excellent bonding agent and be resistant to dissolution by the glass. Attractive as this idea is, it is unsubstantiated by any indications of carbon in samples analyzed by both a LECO carbon analyzer and $x$-ray photoelectron spectroscopy (XPS) surface analysis. Thus, it is not known why sugar decreased melting rates in PSCM-21. 


\section{WASTE VARIABILITY STUDY DESIGN}

Because of segregation of the liquid wastes stored in the tanks at West Valley and other similar factors, it is reasonable to assume that the waste portion of the feed stream will exhibit some variability. In addition, other feed additives may occasionally be present in off-normal amounts through human error. At West Valley, final feed analysis is heavily relied upon to ensure that the feed supplied to the melter, and the resulting glass, are within acceptable limits.

While the glass produced by the vitrification facility over its period of operation will be the reference glass (presently WV-205), it is necessary to know the effect of departures of several feed stream ingredients from nominal values. Once these effects are known, it will be possible to make an informed judgment about whether modifications to other chemicals in the feed composition are needed to mitigate the impacts of off-normal compositions. The usual effect of such modifications will be to increase the total anount of glass, with corresponding increases in the number of canisters and final disposal costs. Most of these deviations from the nominal feed stream composition will be of no great consequence, but some may be.

To determine possible glass composition variations, a computer spreadsheet program was developed using Lotus 1-2-3 to model the vitrification feed blending process. A schematic of the process is shown in figure 5.

The variability model logic is flow-charted in Figure 6 . The model worked by multiplying the plutonium-uranium extraction (PUREX) and thorium extraction (THOREX) nominal waste streams by factors to account for waste uncertainty, waste variability, and human error in batching the streams together. The zeolite strean was assumed to have a precisely known non-variable composition, but was multiplied by a factor to account for human batching error. These waste streams were added together to obtain the "resultant waste" shown on the flow chart. The "resultant waste" composition was then multiplied by factors to account for errors in its chemical analysis, giving an "apparent waste" composition. An attempt was made in each case to add glass formers to obtain a final glass composition close to that of WV-199, which was the reference 


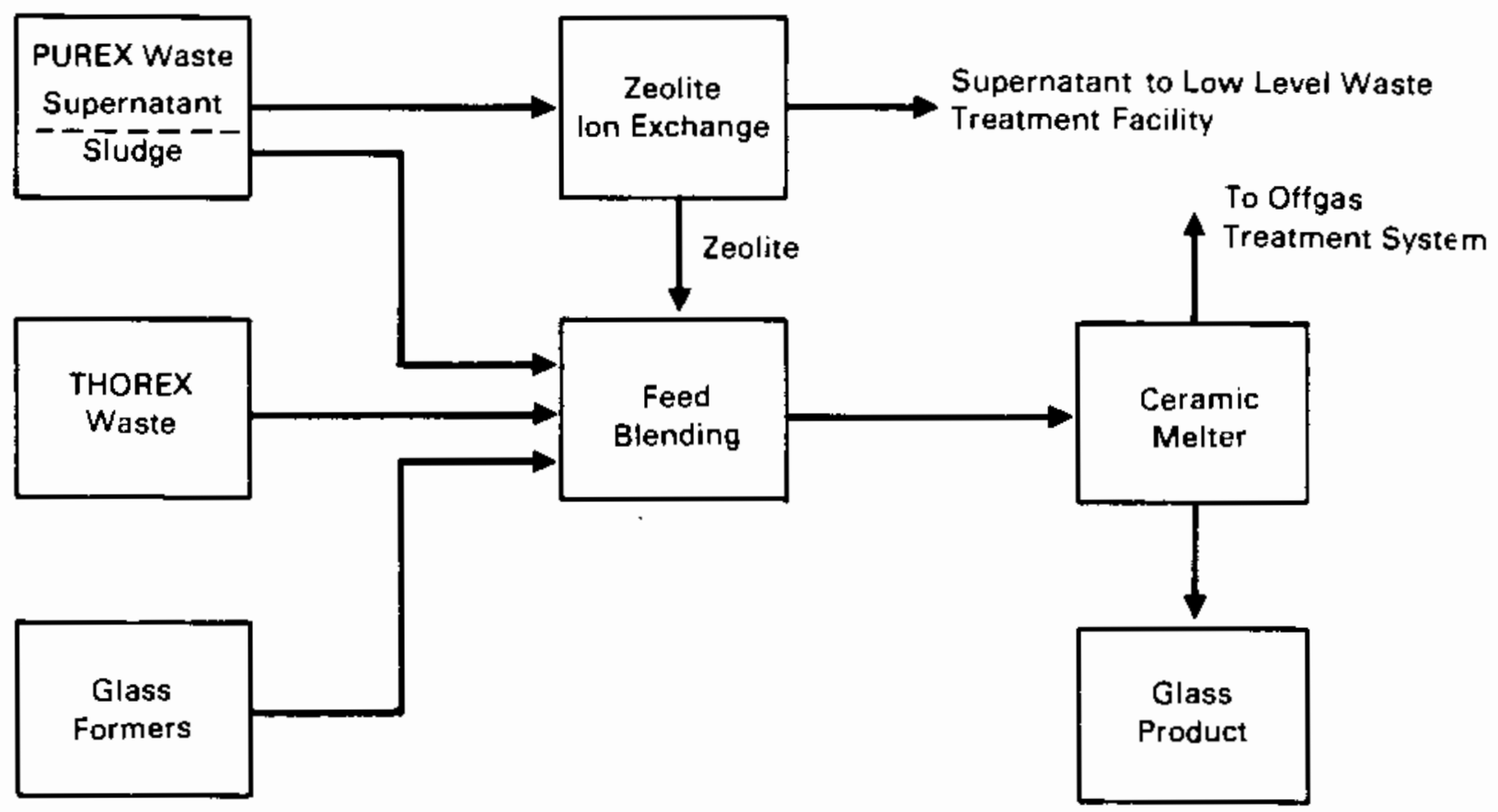

FIGURE 5. The Logic Process Used to Design the Waste Variability Study

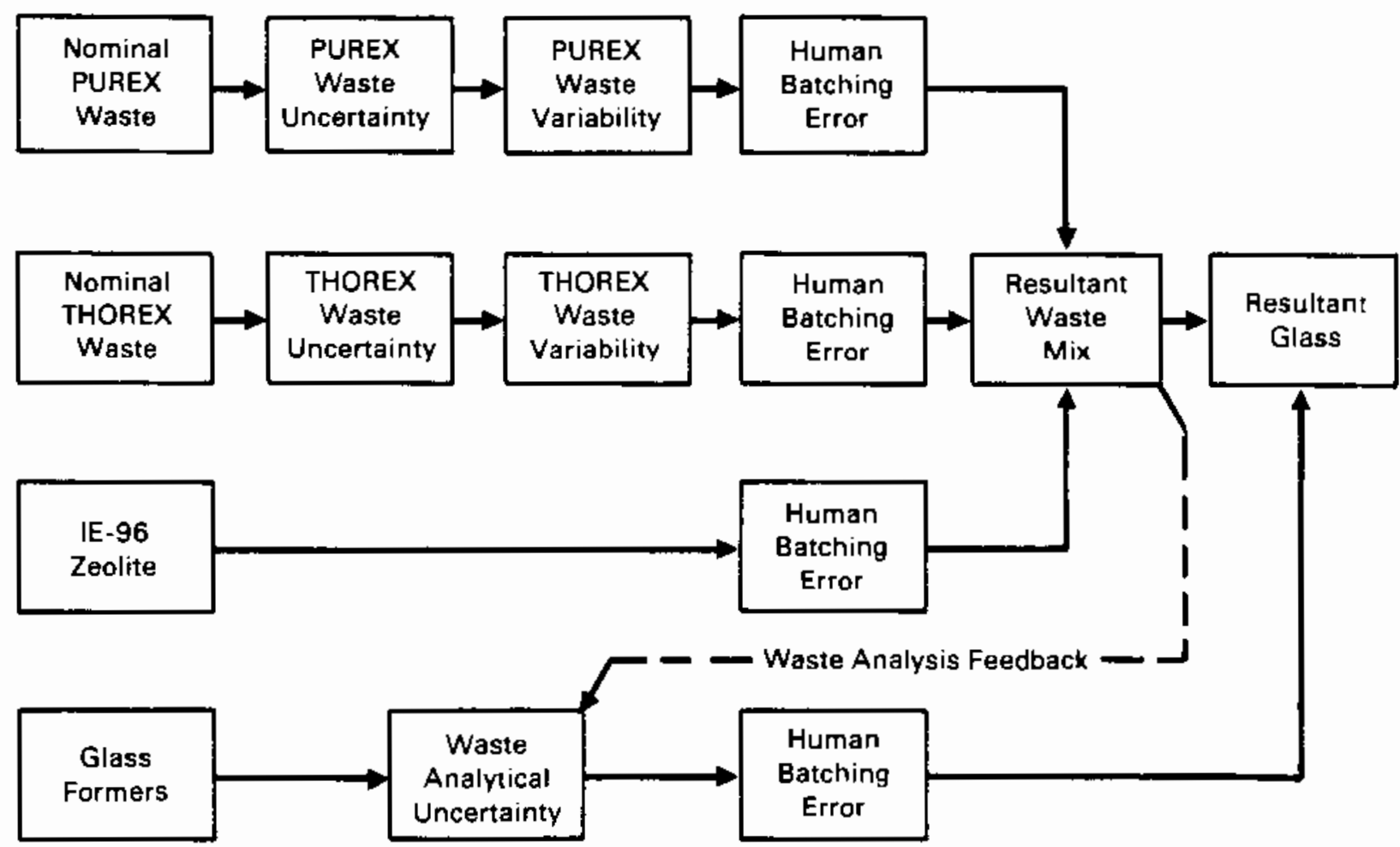

FIGURE 6. Waste Variability Model Logic 
composition at the time the study was designed. These glass former additions were multiplied by factors to account for human batching errors, then added to the "resultant waste" to obtain the final glass composition. The factors used in the model to account for potential variations are outlined in Table 3 .

The variability model was used to calculate possible glass compositions with the highest and lowest achievable amounts of the 12 compounds of interest. These compounds are $\mathrm{Fe}_{2} \mathrm{O}_{3}, \mathrm{P}_{2} \mathrm{O}_{5}, \mathrm{Al}_{2} \mathrm{O}_{3}, \mathrm{Cr}_{2} \mathrm{O}_{3}$, ThO $\mathrm{O}_{2}, \mathrm{SiO}_{2}, \mathrm{SO}_{3}, \mathrm{~B}_{2} \mathrm{O}_{3}, \mathrm{Na}_{2} \mathrm{O}$, $\mathrm{UO}_{2}, \mathrm{CaO}$, and $\mathrm{RE}_{2} \mathrm{O}_{3}$ (rare earth oxides). The results of the computer model showed that, because of the nature of compounded errors, individual compounds usually will not vary independently, but will generally be associated with variations in other components.

The final result of the experimental design was to provide a prioritized list of glass compositions for experimental testing. While compiling this list, the computer-based system variability study (SVS) was considered; the SVS gives an idea of the possible composition variations to be expected when operating the West Valley plant. Existing experimental information was considered, such as that from the statistically designed glass development (SDGD) study (Chick et al. 1984) and subsequent work. In compiling the list, top priority was given to those composition variations that would be expected to have the largest effect on properties, and to those properties whose composition dependence is least known.

The SDGD study produced empirical models that can be used to predict several properties of the oxide melt and glass product with respect to wide variations in the concentrations of seven oxide components: $\mathrm{SiO}_{2}, \mathrm{P}_{2} \mathrm{O}_{3}, \mathrm{Na}_{2} \mathrm{O}$, $\mathrm{CaO}, \mathrm{Al}_{2} \mathrm{O}_{3}, \mathrm{Fe}_{2} \mathrm{O}_{3}$, and waste mix. Properties covered well by these models included melt viscosity and electrical conductivity, crystallinity produced by the slow cooling of canistered glass, and several short-term leaching parameters. However, the empirical models could not predict the effects of variation within the waste mix component, since it was treated as a fixed mixture of 13 oxides in the SDGD study. Important properties of the melter feed that were not tested during the SDGD study included melting rate and secondary phase formation (crystals and immiscible liquids) in the melter. The list of 
TABLE 3. Model Factors Used to Account for Potential Feed Stream Variations

\begin{tabular}{|c|c|c|c|c|}
\hline $\begin{array}{c}\text { Type of } \\
\text { Variability }\end{array}$ & $\begin{array}{l}\text { PUREX } \\
\text { Waste }\end{array}$ & $\begin{array}{l}\text { THOREX } \\
\text { Waste }\end{array}$ & Zeolite & Glass Formers \\
\hline Waste Uncertainty & $\begin{array}{l}\text { Amount of } \mathrm{Fe}_{2} \mathrm{O}_{3} \text { and } \mathrm{P}_{2} \mathrm{O}_{5} \\
\text { assumed constant. } \\
\text { Fission products assumed } \\
\text { to vary } \pm 10 \% \text {, all other } \\
\text { waste constituents vary } \\
\pm 20 \% \text {. }\end{array}$ & $\begin{array}{l}\text { Amount of } \mathrm{ThO}_{2} \\
\text { assumed con- } \\
\text { stant. other } \\
\text { constituents } \\
\text { vary } \pm 5 \% \text {. }\end{array}$ & $\begin{array}{l}\text { Zeolite composi- } \\
\text { tion assumed to } \\
\text { be known, no } \\
\text { variation. }\end{array}$ & $N / A$ \\
\hline Waste Variability & $\begin{array}{l}\mathrm{Fe}_{2} \mathrm{O}_{3} \text { and } \mathrm{P}_{2} \mathrm{O}_{5} \text { content } \\
\text { assumed constant. 0ther } \\
\text { const ituents vary by } \\
\pm 10 \% \text {. }\end{array}$ & $\begin{array}{l}\mathrm{ThO}_{2} \text { assumed } \\
\text { to vary } \pm 20 \% \text {. } \\
\text { Other constit- } \\
\text { uents, no } \\
\text { variation. }\end{array}$ & $\begin{array}{l}\text { Zeolite composi- } \\
\text { tion assumed } \\
\text { constant. }\end{array}$ & $N / A$ \\
\hline $\begin{array}{l}\text { Human Batching } \\
\text { Error }\end{array}$ & $\begin{array}{l}\text { Assumed to be } \pm 20 \% \text { on } \\
\text { entire waste stream. }\end{array}$ & $\begin{array}{l}\text { Assumed to be } \\
\pm 20 \% \text { on } \\
\text { entire waste } \\
\text { stream. }\end{array}$ & $\begin{array}{l}\text { Assumed to be } \\
\pm 20 \% \text { on entire } \\
\text { waste stream. }\end{array}$ & $\begin{array}{l}\text { Assumed to be } \pm 20 \% \\
\text { on each individual } \\
\text { glass former. }\end{array}$ \\
\hline Analytical & $N / A$ & $N / A$ & $N / A$ & $\begin{array}{l}\text { Analytical uncer- } \\
\text { tainty of waste } \\
\text { stream sum assumed } \\
\text { to be } \pm 15 \% \text {. Glass } \\
\text { former additions } \\
\text { are based on } \\
\text { analytical results. }\end{array}$ \\
\hline
\end{tabular}


composition variations to be tested for melting properties is longer than the list for oxides, because the oxide property effects are already predictable for six major oxides.

The SVS produced a list of compositions based on credible maximum and minimum variations of 12 oxides. Since the SVS considered variabilities caused mainly by altering the mixing proportions of whole streams of compounds (PUREX, THOREX, zeolite, and the glass formers), the resulting glass compositions do not represent changes in only one component at a time. For example, the highest credible Fe composition also contains increased levels of $\mathrm{Cr}, \mathrm{P}, \mathrm{Ca}$, and other constituents of the PUREX sludge and decreased levels of THOREX constituents and glass formers. This type of complex variability is more probable in the actual plant than the one-at-a-time variation of individual oxides.

The ideal experimental design to gain the information to predict effects of real plant variations would be a 12-component statistically-designed mixture experiment like the SDGD study performed for the seven components. This is the best way to develop predictability for complex variations where more than one component is expected to change at once. However, since such a study would be prohibitively expensive (the number of experiments increases geometrically with the number of components), some compromises were made in the experimental design to gain the maximum information from relatively few tests.

If the experimental program were to use these SVS compositions exclusively, no clear information would be gained on the effects of the individual oxides. On the other hand, testing oxide variations one at a time would not yield any information on the interactive effects between and among the oxides. Therefore, the sVS compositions were used as a guide to credible ranges of variation for the individual oxides and to compile a list of one-at-a-time variations as well as a few combined variations of special interest. Table 4 shows the ranges of the individual oxides determined from the SVS. The $1 x$ values were obtained directly from the study, while the $2 x$ values provide an extra measure of conservatism by doubling the change from the concentration in the nominal glass. For the experimental work, the $2 x$ values were used for oxides present nominally at less than $3.0 \mathrm{wt} \%$, since these have a greater chance of relative variation. 
TABLE 4. Ranges of Individual Oxides Based on SVS Results

\begin{tabular}{|c|c|c|c|c|c|}
\hline \multirow[b]{2}{*}{ Oxide } & \multirow{2}{*}{$\begin{array}{l}\text { Nominal } \\
\text { Glass } \\
\text { WV-199 }\end{array}$} & \multicolumn{2}{|c|}{$\mathrm{High}$} & \multicolumn{2}{|c|}{ Low } \\
\hline & & IX & $2 X$ & IX & $2 X$ \\
\hline $\mathrm{SiO}_{2}$ & 45.22 & 52.86 & 60.50 & 37.44 & 29.66 \\
\hline $\mathrm{B}_{2} \mathrm{O}_{3}$ & 15.56 & 19.63 & 23.71 & 11.97 & 8.38 \\
\hline $\mathrm{Na}_{2} \mathrm{O}$ & 14.23 & 17.12 & 20.01 & 11.39 & 8.55 \\
\hline $\mathrm{CaO}$ & 0.61 & 1.04 & 1.47 & 0.34 & 0.06 \\
\hline $\mathrm{Al}_{2} \mathrm{O}_{3}$ & 2.92 & 4.68 & 6.44 & 1.74 & 0.55 \\
\hline $\mathrm{Fe}_{2} \mathrm{O}_{3}$ & 11.74 & 17.38 & 23.02 & 7.83 & 3.91 \\
\hline $\mathrm{Cr}_{2} \mathrm{O}_{3}$ & 0.20 & 0.37 & $\underline{0.54}$ & 0.11 & 0.02 \\
\hline $\mathrm{RE}_{2} \mathrm{O}_{3}$ & 0.21 & 0.37 & 0.53 & 0.12 & 0.03 \\
\hline $\mathrm{P}_{2} \mathrm{O}_{5}$ & 2.50 & 3.91 & 5.32 & 1.60 & 0.71 \\
\hline $\mathrm{ThO}_{2}$ & 3.57 & 7.42 & 11.27 & 1.59 & 0.00 \\
\hline $\mathrm{UO}_{2}$ & 0.56 & 1.02 & 1.48 & 0.29 & 0.02 \\
\hline $\mathrm{SO}_{3}$ & 0.14 & 0.57 & 0.99 & 0.07 & 0.00 \\
\hline
\end{tabular}

Bold Face Humbers are values chosen for experimental compositions.

Table 5 is a test matrix for the variability experiments, listing 22 glass compositions. The glass formers, $S i$ and 8 , and the strong flux Na are varied both high and low (+ and -) because they are expected to have large effects on melting behavior. The one-at-a-time waste components: $\mathrm{Ca}, \mathrm{Al}, \mathrm{Fe}, \mathrm{Cr}, \mathrm{RE}, \mathrm{P}$, $T h, U$, and $S$ were only tested at their high levels because they pose no problen at low levels. The next three compositions test interactions at the high levels of oxides known to have the potential for producing secondary phases in the melt. The last four compositions represent extremes of expected melting rate, viscosity, electrical conductivity, and chemical durability.

To further reduce the amount of expensive experimental work, some judgments were made on the relative importance of the test variables, placing individual tests on specific compositions in one of five categories: top-, medium-, and low-priority planned experiments ( $A, B$, or $C$ ); experiments that will not be performed because their results are already predictable based on 
TABLE 5. Experimental Variability Test Matrix

\begin{tabular}{|c|c|c|c|c|c|}
\hline $\begin{array}{l}\text { Composition } \\
\text { Variation } \\
\end{array}$ & $\begin{array}{l}\text { Melting } \\
\text { Rate } \\
\end{array}$ & $\begin{array}{c}\text { Secondary } \\
\text { Phase } \\
\end{array}$ & Viscosity & $\begin{array}{c}\text { Electrical } \\
\text { Conductivity } \\
\end{array}$ & $\begin{array}{c}\text { Chemical } \\
\text { Durability } \\
\end{array}$ \\
\hline $\begin{array}{l}\text { Sit } \\
\text { Si- }\end{array}$ & $\begin{array}{l}A \\
B\end{array}$ & $\begin{array}{l}B \\
B\end{array}$ & $\begin{array}{l}P \\
P\end{array}$ & $\begin{array}{l}P \\
P\end{array}$ & $\begin{array}{l}P \\
B\end{array}$ \\
\hline $\begin{array}{l}B+ \\
B-\end{array}$ & $\begin{array}{l}B \\
A\end{array}$ & $\begin{array}{l}B \\
B\end{array}$ & $\begin{array}{l}P \\
P\end{array}$ & $\begin{array}{l}p \\
p\end{array}$ & $\begin{array}{l}B \\
P\end{array}$ \\
\hline $\begin{array}{l}\mathrm{Na}+ \\
\mathrm{Na}-\end{array}$ & $\begin{array}{l}B \\
A\end{array}$ & $\begin{array}{l}B \\
B\end{array}$ & $\begin{array}{l}c \\
c\end{array}$ & $\begin{array}{l}c \\
c\end{array}$ & $\begin{array}{l}B \\
P\end{array}$ \\
\hline $\begin{array}{l}\mathrm{Ca}+ \\
\mathrm{A} 1+\end{array}$ & $\begin{array}{l}B \\
A\end{array}$ & $\begin{array}{l}A \\
A\end{array}$ & $\begin{array}{l}P \\
P\end{array}$ & $\begin{array}{l}P \\
P\end{array}$ & $\begin{array}{l}P \\
P\end{array}$ \\
\hline $\begin{array}{l}\mathrm{Fe}+ \\
\mathrm{Cr}+\end{array}$ & $\begin{array}{l}B \\
B\end{array}$ & $\stackrel{A}{A}$ & $\begin{array}{l}P \\
I\end{array}$ & $\begin{array}{l}\text { P } \\
\text { I }\end{array}$ & $\begin{array}{l}P \\
I\end{array}$ \\
\hline $\begin{array}{l}\text { RE+ } \\
\mathrm{P}+\end{array}$ & $\begin{array}{l}\text { A } \\
\text { A }\end{array}$ & $\stackrel{A}{A}$ & $\begin{array}{l}\mathrm{I} \\
\mathrm{C}\end{array}$ & $\begin{array}{l}\mathrm{I} \\
\mathrm{C}\end{array}$ & $\begin{array}{l}\mathrm{I} \\
\mathrm{C}\end{array}$ \\
\hline $\begin{array}{l}\text { Th+ } \\
\text { Ut }\end{array}$ & $\begin{array}{l}A \\
A\end{array}$ & $\begin{array}{l}A \\
A\end{array}$ & $\begin{array}{l}c \\
c\end{array}$ & $\begin{array}{l}c \\
c\end{array}$ & $\begin{array}{l}c \\
c\end{array}$ \\
\hline $\begin{array}{l}\mathrm{S}+ \\
\mathrm{RE}+\mathrm{Ca}+\mathrm{P}+\end{array}$ & $\begin{array}{l}\mathrm{A} \\
\mathrm{A}\end{array}$ & A & $\begin{array}{l}C \\
B\end{array}$ & $\begin{array}{l}\text { C } \\
\text { I }\end{array}$ & $\begin{array}{l}\text { C } \\
\text { I }\end{array}$ \\
\hline $\begin{array}{l}\mathrm{Cr}+\mathrm{Fe}+ \\
\mathrm{Th}+\mathrm{Ca}+\mathrm{P}+\end{array}$ & $\begin{array}{l}A \\
A\end{array}$ & A & $\begin{array}{l}B \\
B\end{array}$ & $\begin{array}{l}\mathrm{I} \\
\mathrm{I}\end{array}$ & I \\
\hline $\begin{array}{l}\mathrm{Si}+\mathrm{Al}+ \\
\mathrm{B}-\mathrm{Na}-\end{array}$ & A & A & $\begin{array}{l}B \\
B\end{array}$ & $\begin{array}{l}B \\
B\end{array}$ & $\begin{array}{l}\mathrm{p} \\
\mathrm{p}\end{array}$ \\
\hline $\begin{array}{l}\mathrm{Si}-\mathrm{Al}= \\
\mathrm{B}+\mathrm{Na}^{+}\end{array}$ & I & I & $\begin{array}{l}c \\
c\end{array}$ & $\begin{array}{l}c \\
c\end{array}$ & $\begin{array}{l}\text { B } \\
\text { B }\end{array}$ \\
\hline
\end{tabular}

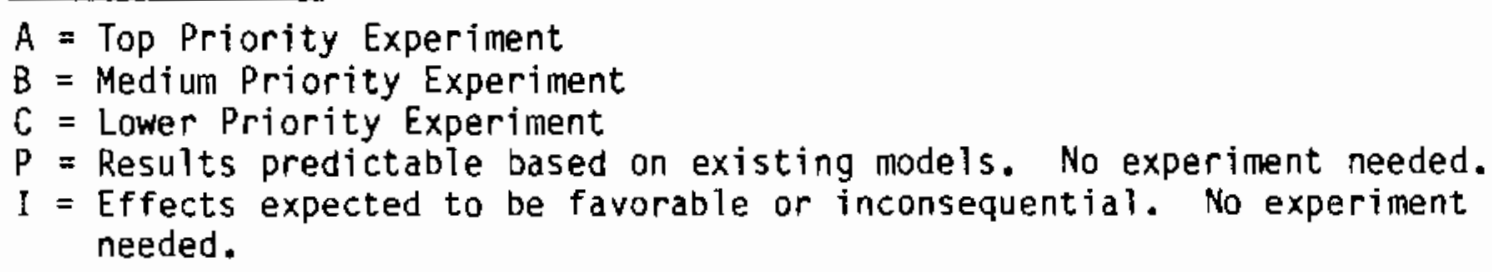

the empirical models (P); and experiments that were not performed because the results are expected to be inconsequential (I). All of the meiting behavior tests of melting rate and secondary phase formation are classed in the top- and medium-priority levels, except for the last two variations which are judged to not have unfavorable effects. 
Table 6 lists the 22 test compositions. For those compositions in which no waste mix oxides are varied, five oxide properties predicted by the empiri* cal mode1s from the SDGD study are listed. The predicted temperature at which the melt will reach $100 \mathrm{P}$ viscosity, designated $\mathrm{T} 100 \mathrm{P}$, ranges from $930^{\circ} \mathrm{C}$ for the low-Si/low-Al glass to $1356^{\circ} \mathrm{C}$ for the high-Si/high-Al glass. The latter composition may not be processable in the present melter design. As shown previously in Table 5, several of these predicted properties were scheduled for confirmation testing at medium- or low-priority levels.

In the form eventually completed, the waste variability study examined tw') melting characteristics of these melter feeds which affect melter performance: melting rate and secondary phase formation.

In the time which passed between planning the study and executing it, the nominal (target) glass composition was changed from WV-199 to WV-205, so the glass compositions were adjusted accordingly with the variability model discussed in the SVS. Compositions with high and $\mathrm{low}_{2} \mathrm{~K}_{2} \mathrm{O}$ and $\mathrm{Li}_{2} \mathrm{O}$ were added to the study. Due to limited time and funding, only the highest priority variations and properties were examined. The expected worst cases were chosen, those with two or three oxides varying simultaneously.

Melting rate and secondary phase tests were performed on the nominal glas:s composition (WV-205) and four of the possible glass variations with simulated melter feeds: glass with high alkali content, glass with low alkali content ( $\mathrm{Na}, \mathrm{K}$, and $\mathrm{Li}$ ); glass with high RE, Ca, and $\mathrm{P}$ content; and glass with high Fe and $\mathrm{Cr}$ content.

\section{RESULTS AND DISCUSSION}

The studies outlined above were not all carried out. Nevertheless, the work on melting rates and secondary phases was sufficiently informative to justify inclusion here. Experimental methods are discussed below, along with the results and discussion. 
TABLE 6. Compositions Used in the Variability Study and Predicted Property Values

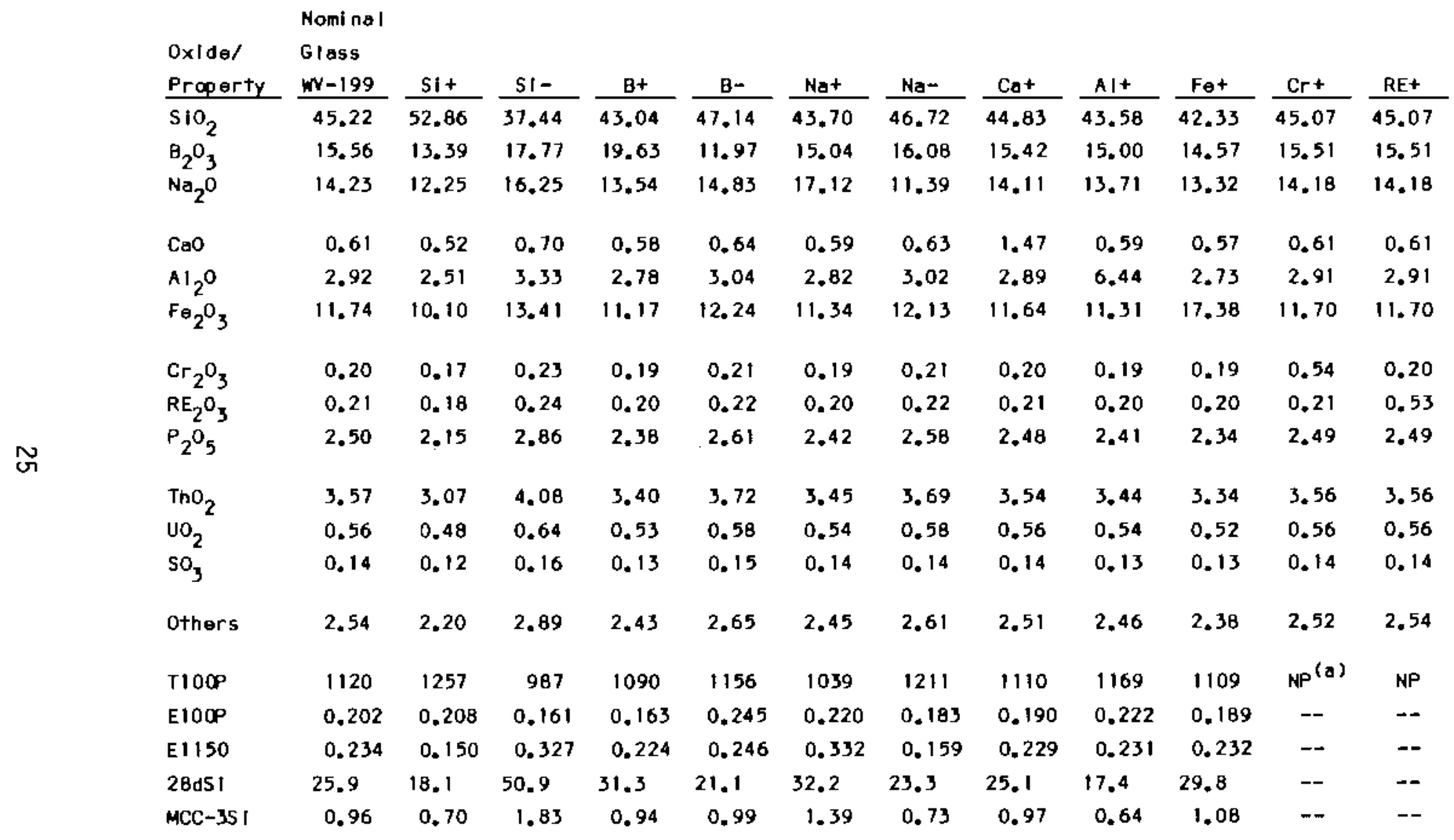

(a) Properties are not predlctable for this composition because a Waste Mlx component has changed. Tloop = Predicted temperature for viscosity to be 100 Polse.

El OOP = Predicted electrlcal conductivity at T100P.

El150 = Predicted electrical conduct 1 vity at $1150^{\circ} \mathrm{C}$.

28dSI = Predicted sillicon release In 28 -day leach test.

MCC-3Si = Predicted sllicon release in MCC-3 leach test. 
Melting Rates

The melting test measured disappearance of the cold cap over time. Feed was introduced into a crucible containing a molten glass "base" in two 15-mL pours; the crucible was removed after a set elapsed time after the last pour. The crucible was then halved and a tracing of the cold cap was made on a plastic film, which was cut out and weighed to measure its relative area. Plots were then made of the relative areas (mg cold cap) versus time elapsed. The slope of the "best" line drawn through these points (determined with least squares linear regression) is the "melting rate" of the glass, expressed in units of $\mathrm{mg}$ cold cap/min. The plots contain much scatter as this method is extremely dependent on operator consistency and cold-cap interpretation.

The results of melting rate determination are tabulated in Table 7. Melting rates for several different composition variations are combined in Figure 7.

The melting rates are expressed as disappearance of melt cold cap over elapsed time. The more negative this rate, the faster is the melting of the feed. Feeds that have a tendency to produce thick cold caps can yield relatively high melting rates which are misleading. It is therefore necessary to also consider cold-cap burn-off times; i.e., a cold cap is burned off when it is no longer discernible, and the feed is totally melted. The "Initial Cold Cap" column in Table 7 gives the point where the melting rate line intersects

\section{TABLE 7. Melting Rates and Cold-Cap Burn-0ff Times}

\begin{tabular}{|c|c|c|c|}
\hline WV-205 G1ass Variations & $\begin{array}{l}\text { Melting Rate, } \\
\text { mg cold cap/min }\end{array}$ & $\begin{array}{c}\text { Initial Cold } \\
\text { Cap, mg } \\
\end{array}$ & $\begin{array}{l}\text { Observed Cold Cap } \\
\text { Burn-0ff Time, min }\end{array}$ \\
\hline Nomina 1 & -18.90 & 107.8 & 5.0 \\
\hline Nominal & -7.15 & 63.6 & 9.0 \\
\hline \multicolumn{4}{|l|}{ With $35 \mathrm{~g} / \mathrm{L}$ added sugar } \\
\hline $\mathrm{Na}+\mathrm{K}+\mathrm{Li}+$ & -10.28 & 58.9 & 5.0 \\
\hline $\mathrm{Na}-\mathrm{K}-\mathrm{L} i-$ & -7.28 & 72.1 & 10.0 \\
\hline $\mathrm{Fe}+\mathrm{Cr}^{+}$ & -9.30 & 68.7 & 6.0 \\
\hline $\mathrm{RE}+\mathrm{Ca}+\mathrm{P}+$ & -10.71 & 89.7 & 8.0 \\
\hline
\end{tabular}




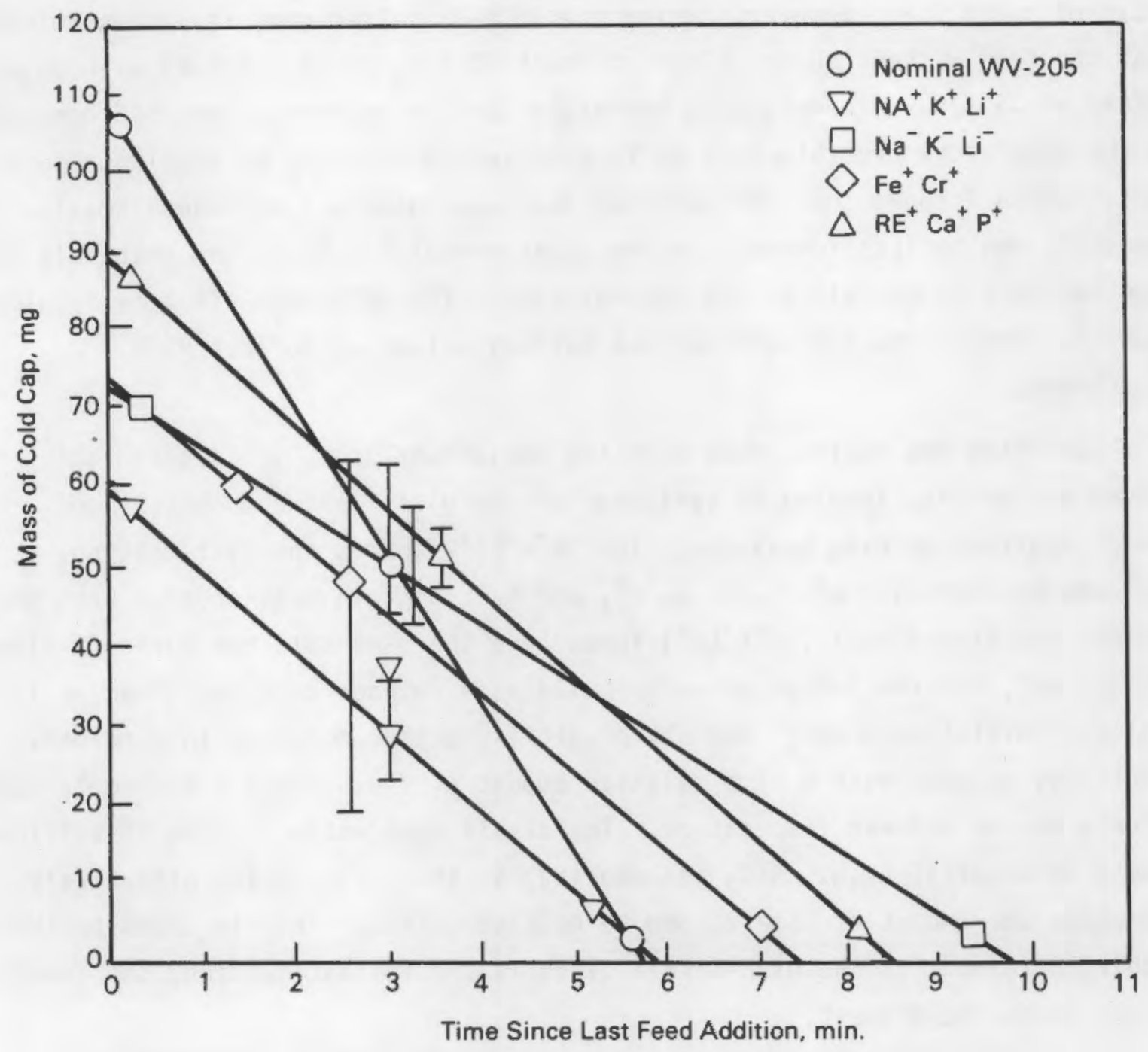

\section{FIGURE 7. Melting Rates for Several Composition Variations}

the abscissa. This is not the "true" cold-cap thickness at time zero but is listed here to give an idea of the relative cold-cap thickness of the melt for comparison purposes.

As shown in Table 7, the nominal glass feed has the highest melting rate, with that of nominal feed with added sugar being much lower. The addition of sugar as a reducing agent to glass feeds has been shown to reduce "foaming" in the PSCM at PNL and to enhance melting behavior. The nominal WV-205 feed contains sodium oxalate as a reducing agent. Previous standard practice has been to add reducing agent in the form of sugar in order to achieve an $\mathrm{Fe}^{+2} / \mathrm{Fe}^{+3}$ 
ratio of about 0.2 . However, during the PSCM-21 melter run, it was established that the feed without sugar melted at about $60 \mathrm{~L} / \mathrm{h}$, while the feed with sugar melted at $35 \mathrm{~L} / \mathrm{h}$. Attempts were therefore made to replicate the PSCM behavior in the laboratory crucible test to further verify scale-up of the laboratory data. Table 7 shows that the relative cold-cap thickness is indeed smaller (possibly due to less foaming) in the sugar-containing feed, but that this feed does not melt as quickly as the nominal feed. The melt burn-off time is almost doubled. Hence, the lab melting rate determinations do reflect PSCM experience.

Comparing the nominal feed with the variations used, it is seen that system variability leading to variation of the glass feed composition does directly affect melting behavior. The $\mathrm{Na}^{+} \mathrm{K}^{+} \mathrm{Li}^{+}$feed is the best-melting, followed by nominal, $\mathrm{Fe}^{+} \mathrm{Cr}^{+}, \mathrm{RE}^{+} \mathrm{Ca}^{+} \mathrm{P}^{+}$, and $\mathrm{Na}^{-} \mathrm{K}^{-} \mathrm{Li}^{-}$, in that order. Both the nominal and high alkali $\left(\mathrm{Na}^{+} \mathrm{K}^{+} \mathrm{Li}^{+}\right.$) feeds have the same cold cap burn-off times ( 5 minutes), but the latter seems to build up a thinner cold-cap shown by its smaller "initial cold cap," thereby predicting better behavior in a melter. Generally, glasses with a high relative amount of flux (alkali) will melt more quickly and at a lower temperature. The alkali apparently aids in dissolving grains of material (e.g., $\mathrm{SiO}_{2}$ and zeolite) in the glass, which effectively decreases the amount of time needed to melt the glass. This is shown by the results obtained, as the high-alkali glass is the fastest melting, the lowalkali glass the slowest.

The poor melting behavior of the $\mathrm{Fe}^{+} \mathrm{Cr}^{+}$and $\mathrm{RE}^{+} \mathrm{Ca}^{+} \mathrm{P}^{+}$glasses was expected. Glasses relatively high in iron content, such as the $\mathrm{Fe}^{+} \mathrm{Cr}^{+} \mathrm{glass}$, have been shown to form a relatively large quantity of crystals, mostly spinels. Calcium phosphate phases have been shown to form in glasses with high calcium content such as the $\mathrm{RE}^{+} \mathrm{Ca}^{+} \mathrm{P}^{+}$glass. These phases are believed to interfere with melting of silica and zeolite grains by physically isolating them from the fluxing liquids within the cold cap.

Secondary Phases

This section describes the observation of secondary phases such as crystals and/or immiscible liquids on the melt surface. The observations are made by introducing feed into a hot crucible in three $15-\mathrm{mL}$ pours. Visual 
observation of the melt surface is made after 2 hours, and the crucible is "pulled from the furnace after 4 hours. If a film or crystals are observed on the surface, a thin section of the glass is cut, polished, and observed under a microscope to characterize these secondary phases.

Secondary phases were observed in all of the glasses with the exception of the high-alkali glass. This would be expected, as the high flux content of the high-alkali glass should enhance vitrification. Relative surface areas of films were noted at 2 hours, and reduction of this area was observed at 4 hours. The surfaces of the low-alkali glasses were completely covered with surface scum at 2 and 4 hours. The fraction of the glass surfaces covered with film/scum after 4 hours was as follows: $\mathrm{Na}^{+} \mathrm{K}^{+} \mathrm{Li}^{+}(0 \%)$, nominal $(25 \%), \mathrm{Fe}^{+} \mathrm{Cr}^{+}$ $(60 \%), \mathrm{RE}^{+} \mathrm{Ca}^{+} \mathrm{p}^{+}(90 \%)$, and $\mathrm{Na}^{-} \mathrm{K}^{-} \mathrm{Li}^{-}(100 \%)$.

Thin sections of the four melts with secondary phases present were examined in an optical microscope. The nominal glass was found to contain very fine cubic black crystals, less than $2 \mu \mathrm{m}$ on a side, believed to be spinels. The crystals were evenly distributed throughout the melt, with some clumps observed at the surface of the melt. These crystals were the smallest in size observed in all four glasses.

The $\mathrm{Na}^{-} \mathrm{K}^{-} \mathrm{Li}^{-}$was found to contain about the same relative amount of cubic crystals as the nominal glass, but they were larger. Bigger clumps of these crystals were seen $a 11$ along the surface; some of these were impervious to 1ight. A greater number of red-brown crystals, which appeared to be hematites, were also observed. This increase in the amount of crystals is possibly caused by less efficient melting due to the reduced amount of flux present (relative to the nominal glass).

Spinel-type crystals, larger and more numerous than in the nominal melt, were observed scattered densely in the $\mathrm{Fe}^{+} \mathrm{Cr}^{+}$me1t. Large clumps of these, many impervious to light, were observed at the surface. A few crystals, which appeared to be hematites, were observed along the bottom of the melt. More crystals were formed due to the higher relative iron and chrome contents of this glass. 
The greatest relative amount of crystals was observed in the $\mathrm{RE}^{+} \mathrm{Ca}^{+} \mathrm{P}^{+}$ melt. The concentration of the crystals increased toward the bottom of the melt. Black cubic crystals, larger than those in the nominal glass, were observed in randomly scattered clumps throughout the glass. Large clumps of these were observed at the surface, more than in any of the other melts. Redbrown crystals, which appeared to be hematites, were observed; the largest concentration of these was found toward the bottom of the melt. Some of the black clumps may actually be calcium phosphate crystals, as mentioned earlier.

It was originally intended that an abbreviated version of the remaining experimental matrix (Table 5) be completed in FY 1986, and this work was proposed to West Valley. Shifting priorities at West Valley resulted in a lack of funding for the work, which was stopped at this point. 


\section{PROCESS PROBLEMS}

Use of a joule-heated melter in a hot cell to produce high-level nuclear waste glass for a long period on a continuous basis, as will be done at West Valley, demands freedom from several classes of problems. These problems are fairly easily circumvented in a normal glass production environment, but must be more thoroughly understood and solved in the West valley case.

\section{FOAMING}

Early melter trials conducted on the original glass composition chosen for use with the West Valley waste stream (WV-182) indicated the existence of a problem not previously seen in the melting of nuclear waste glasses--the development of stable foams in the melter. These foams developed during normal melter operation from gas bubbles rising to the surface of the molten glass. The gas bubbles accumulated at the surface and formed a stable foam, which expanded upward into the space above the molten glass where it cooled and became a very serious problem.

Stable foams produce several undesirable effects. Among these are blockage of access to the hot glass surface for new feed, insulation of the glass which may cause higher glass temperatures, and possible disruption of the electrical power distribution in the melter. The correct operator's response to an observed foaming incident is to decrease power and stop feed until the foam collapses and the desired melt temperatures are restored. Frequent foaming translates into considerable melter down-time and therefore must be minimized.

To determine the cause of the glass foaming and to test remedial actions, the apparatus in Figure 8 was extensively used. Basically, the apparatus consisted of a furnace provided with an alumina liner tube with water-cooled end fittings, making it gas-tight. The alumina tube could be evacuated by a vacuum pump. A sight glass was provided so that the foaming tendency of the test glass contained in an alumina crucible could be observed. Figure 9 shows the "reboil pressure" measured in this apparatus for a variety of waste glasses. 


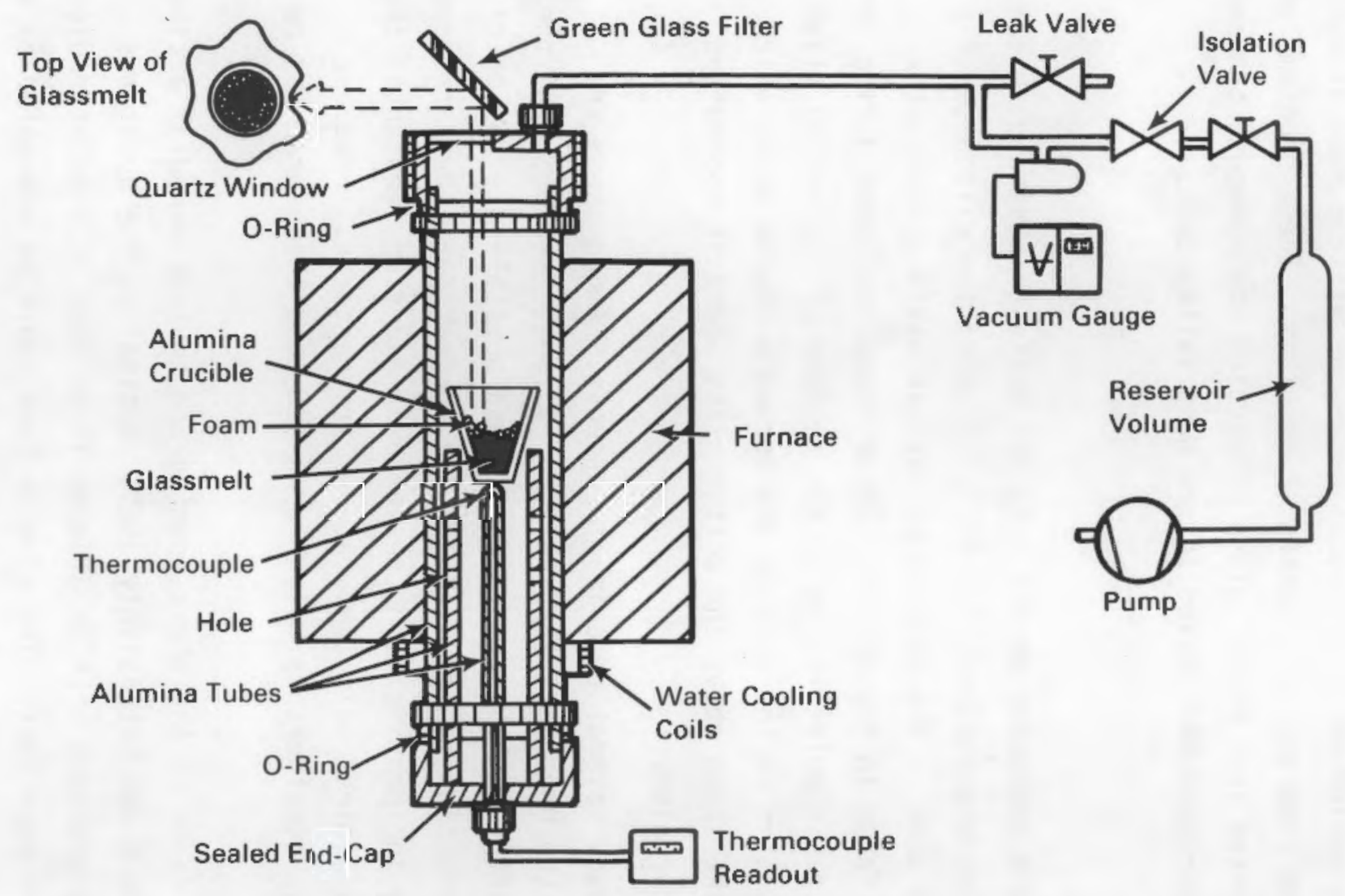

FIGURE 8. Apparatus Used to Measure Reboil Pressures of Molten Glasses for Studying Foaming 
The general trend shown in Figure 9 is that reboil pressure values are higher (and hence foaming is more likely) in glasses collected from melter tests that experienced significant foaming than in glasses from melter tests relatively free of foaming events. The stippled region is an estimated range of reboil pressures that appears to define the boundary between glasses with high and low foaming tendencies. This correlation is important because it establishes a link between laboratory data and actual melter observations.

Three gases were considered as possible causes for the formation of stable foams: oxygen, vapor, and the oxides of sulfur. These can be liberated from the melt by the increase in temperature affecting their stability. The shift

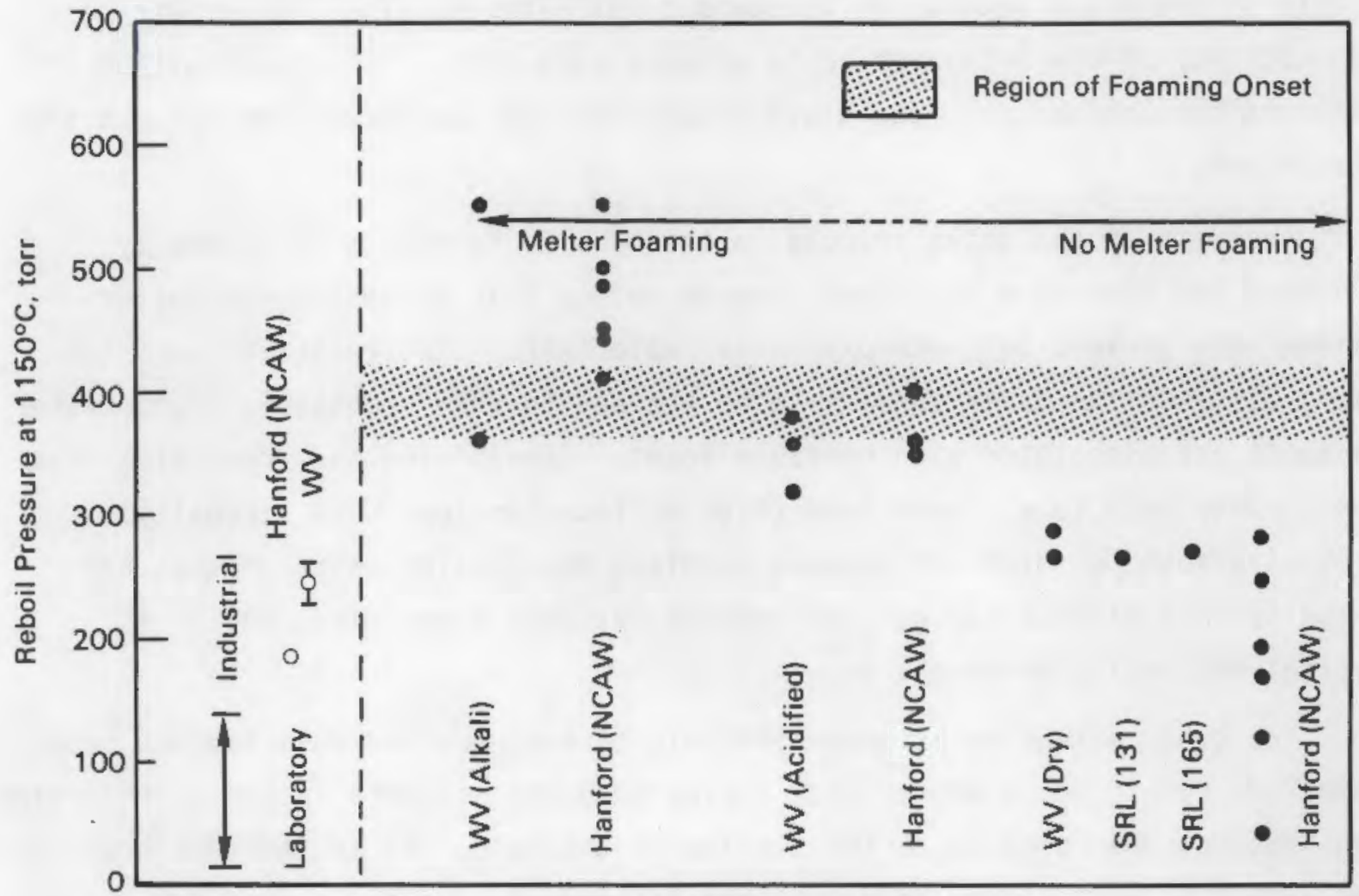

Melter Glass Types

FIGURE 9. Reboil Pressures of a Variety of Waste Glasses, Correlated with Their Tendency to Foam During Actual Melting 
in oxidation state between oxidized ferric iron and reduced ferrous iron can liberate noticeable quantities of oxygen, and similar reactions can liberate water or sulfur oxides.

By adding reductants such as carbon to the feed, it was found that the tendency to form stable foams dropped dramatically, and measurement of the ferrous/ferric iron ratio showed that stable foams were only produced under oxidizing conditions. The addition of enough carbon to reduce the glass to a ferrous/ferric iron ratio of 0.2 to 0.3 was sufficient to disrupt the stability of the foams. Reduction with carbon sources can be overdone, as indicated by the upper limit on ferrous/ferric iron ratios above; a glass that is too reduced will in turn reduce some of its metal oxides, and these metallics can settle in the glass because of the density difference. The high electrical conductivity of the metallics could produce catastrophic short-circuiting if they are not drained with the glass before they bridge the volume between the electrodes.

Analysis of the gases trapped in the bubbles forming a PSCM foam by crushing the foam in a mass spectrometer showed that no noticeable sulfur oxides were present but both oxygen and water were. The relative concentrations of these two gases appears to be the key to foam stability; higher water contents are associated with unstable foams. Considering the properties that would contribute to a stable foam (high surface tension, high viscosity), viscosity must be ruled out because oxidized West Valley waste glasses are actually less viscous ( $30 \mathrm{P}$ ) than reduced Savannah River glass (50 P) at typical processing temperatures.

The surface tension is more difficult to evaluate and thus has not been compared, but it would appear that the water decreases this factor to the point that bubbles are ruptured at the surface of the melt. As an indirect proof of the effect of water vapor on foam stability, dry oxygen and oxygen saturated with water (at room temperature, partial pressure $0.03 \mathrm{~atm}$ ) were bubbled through a typical homogeneous West Valley glass. There was a marked difference in the stability of the bubbles, with those from the wet oxygen rupturing immediately at the surface while those from the dry gas formed a stable foam. 
To avoid the undesirable effects of stable foams in the processing of West Valley nuclear waste glass compositions, it is necessary to add reductants to the glass feed. The easiest way to accomplish this is to add soluble sources of carbon to the water-based feed; likely candidates include sugar, formic acid, and oxalic acid. It was experimentally determined that these should be added to the point that the resulting glass has a ferrous/ferric iron ratio of 0.2 to 0.3 . This has been done in extensive laboratory experimentation, as well as in PSCM campaigns, and appears generally to have solved the foaming problem. Unfortunately, there is no way to calculate the amount of reductant to be added to the feed a priori. The only known method is to melt a series of test glasses containing known amounts of reductants and evaluate either the ferrous/ferric iron ratio or the foaming tendency. Either of these properties is fairly easy to evaluate, but there is no proven real-time method at this time.

Of the redox control agents tested to date, sugar is one of the most popular. Figure 10 shows a chronological record of melter run PSCM 19, during a period when sugar was being tested for effectiveness and was thus added in different amounts. The reboil pressure measurements corresponded well with the sugar additions; lower reboil pressures resulted from the more reduced nature of the glass as more sugar was added. Reboil pressure immediately rose when sugar additions ceased. The ferrous/ferric iron ratio was unchanged until sugar addition was $75 \mathrm{~g} / \mathrm{L}$ of feed, at which the ratio rose as predicted by laboratory experiments. The ratio fell quickly after sugar was no longer added.

At the time of this writing, the viability of sugar for redox control is still not finally determined. During the PSCM-21 melter run, a feed was used which was, by laboratory testing, determined to require $35 \mathrm{~g} / \mathrm{L}$ of sugar for redox control. This feed was melting satisfactorily at about $35 \mathrm{~L} /$ hour; sugar was eliminated from the feed as an experiment and the processing rate increased to over $55 \mathrm{~L}$ /hour, a substantial improvement. Two small foaming incidents occurred after the sugar was eliminated, but these were easily controlled and caused little difficulty. 


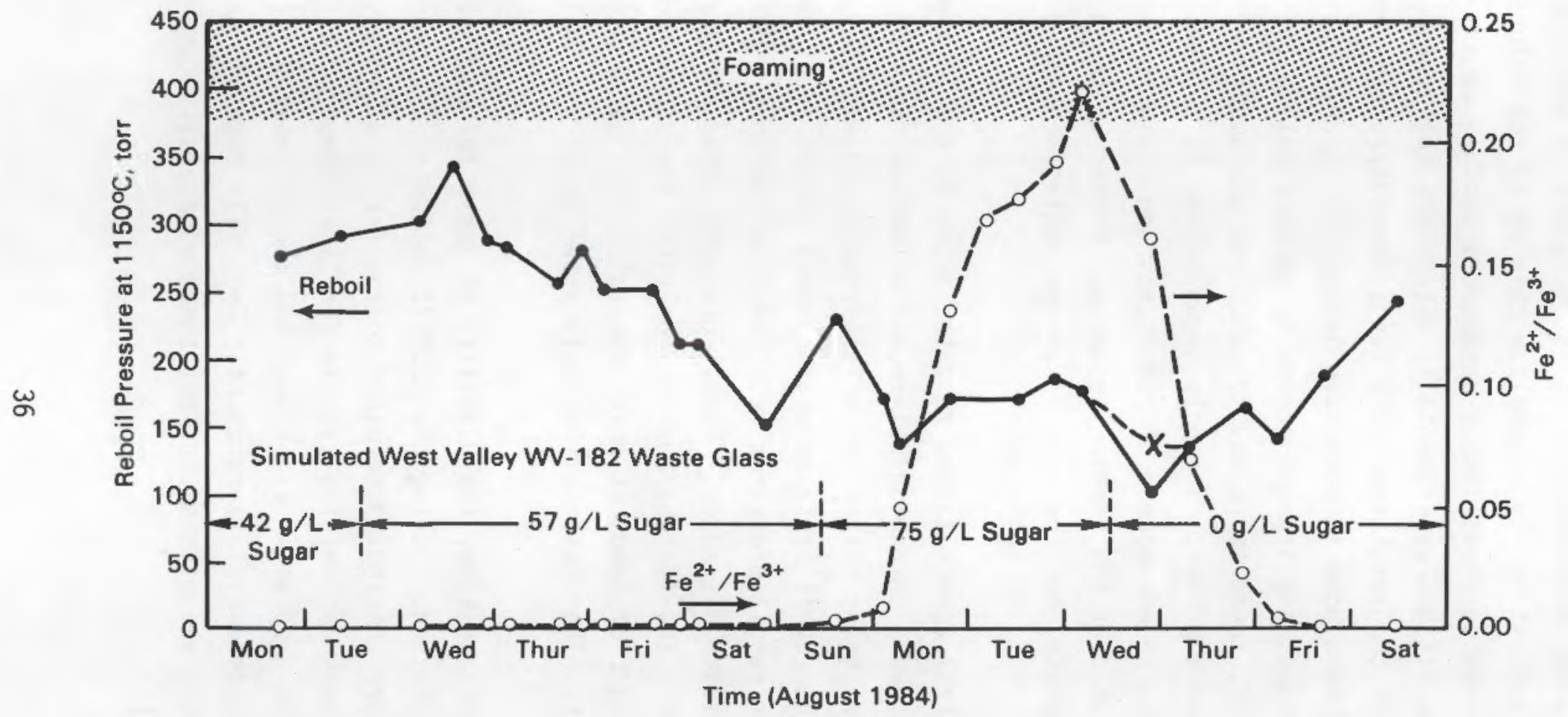

FIGURE 10. Chronological Record of Melting Behavior Observed During PSCM-19, Showing the Effect of Sugar Additions on Melting Rate 
Subsequent laboratory testing confirmed the correlation between sugar and lower processing rates. Although the cause for this lower rate was sought, it was not determined. Among the hypotheses tested were crystalline phases at the top surface and residual carbon acting as a cement for partially melted feed. If sugar continues to be used as a reductant, perhaps it would be prudent to decrease the amount to correspond to a ferrous/ferric iron ratio nearer to 0.1 as a compromise between having some reductant present and suffering low processing rates as a consequence. It is not known if other reductants produce these processing rate limitations; this should also be investigated.

Some reductants, most notably formic acid, must be used with caution because of the possibility of flammable gases being present in the decomposition products of the reductant. At this time there is little data on the presence of such gases, but avoiding reductants that could produce them would be prudent.

\section{SURFACE SCUM FORMATION}

A series of laboratory crucible tests was conducted during the development and testing of West Valley glasses to better understand the factors that affect the formation of a surface or "scum" layer that is enriched in undesirable secondary phases. It is common for small particles suspended in a viscous fluid to increase the apparent viscosity of the fluid. The increase in the apparent viscosity of the glass at the surface impedes melting rates. Melting tests were conducted with liquid feeds using the bottom-heated crucible method, wherein feed was sequentially added to an empty, hot crucible until about $40 \mathrm{~g}$ of glass was produced. This final amount was left in the furnace for varying amounts of time, extracted and examined for surface phases. The surface temperature in the test was $1030^{\circ} \mathrm{C}$; the bulk of the glass was heated to about $1100^{\circ} \mathrm{C}$ to mimic the temperature difference encountered in large joule-heated ceramic melters. In most cases, the information gained from the 1-hour test was adequate to evaluate the scum formation potential of a feed. Testing showed that 16-hour scum formation results were equivalent to 1-hour results.

Tests with fully nitrated PSCM-16 feed with and without sugar and with and without the addition of 0.7 wt $\mathrm{CaO}$ did not produce any surface phases, though 
the addition of sugar promoted the bulk crystallization of $\mathrm{Fe}-\mathrm{Cr}$ oxide phases. Tests with WV-182 glass left a surface scum enriched in calcium phosphate and $\mathrm{Fe}-\mathrm{Cr}$ oxide phases similar to those found in the PSCM-19 scum. Glass WV-183 left a less-pronounced surface phase enriched in a rare-earth phosphate and the $\mathrm{Fe}-\mathrm{Cr}$ oxide phases. The rare-earth phosphate was eliminated from the surface of the crucible tests by using the zirconium substitution for uranium and thorium in WV-192, which left a clean surface after 1 hour.

The WV-199N and WV-199n feeds prepared in the laboratory also produced a clean surface after the 1-hour test. It is noted that the WV-199n ECM feed left a surface that was completely covered with scum after 1 hour. The origin of this discrepancy is unknown. The scum collected after the WV-199n ECM test was mostly chromite spinel with minor amounts of calcium phosphate, as identified by metallography and SEM. The WV-202F ECM feed left a thick, vesicular scum in the laboratory test even after 16 hours. The similar-appearing scum collected after the WV-202F ECM test was enriched in the calcium phosphate and $\mathrm{Fe}-\mathrm{Cr}$ phases. Hence, even at the minimum calcium levels attainable, some phosphate phase separation can occur. The partially nitrated WV-202n feed left a scum after 1 hour in the crucible but had a clean surface after 16 hours. This surface phase lacked phosphate phases but contained chromite spinel. WV-203 and WV-205 did not produce surface scums in laboratory tests. Minor amounts of calcium phosphate were found in the surface sample collected after the WV-205 ECM test.

Crucible tests of WV-183RAD and WV-202RAD formulations having uranium and thorium did not produce surface scums. This result was consistent even for a 40-hour test of the WV-202RAD composition. Thus, based on these limited tests, a thorium phosphate phase is not expected to form and impair processing of the eventual radioactive waste.

\section{SLUDGES}

The generic term "sludge" is used to mean virtually any phase in a glass with a density greater than that glass so that settling occurs. When ceramic joule-heated melters are used to melt glass feed, there is some danger that, because of the melter's slow draining, sludge phases might accumulate over 
time. The consequence of this is an eventual short-circuit of the electrodes when the sludge is highly electrically conductive, which in some early designs were inserted from the top and extended to within a few inches of the tank bottom. There has been a report that the Japanese have already experienced a problem with electrical short-circuiting by sludges (Sasaki et al. 1984). In the final West Valley melter design, there are two top-hung electrodes and a bottom electrode so that three-phase power can be used. The vertical separation between top and bottom electrodes is $16 \mathrm{in}$. This design is inherently less subject to short-circuiting, especially since the glass drains from a point $10 \mathrm{in}$. above the bottom electrode.

In the waste glasses being studied, sludge usually refers to iron- or chrome-based spinels or noble metals. Formation of either sludge type is a matter of glass composition, which is, in turn, dependent on the waste stream composition. High iron and chrome levels (>0.5 wt\% $\mathrm{Cr}_{2} \mathrm{O}_{3}$ ) tend toward spinel formation, and the waste stream always contains some noble metals ( $R u, R h, P a)$ of very limited solubility in the waste glass. The $\mathrm{RuO}_{2}$ is only soluble to about 0.005 wt $\%$ in these glasses.

The settling and accumulation of these materials at the melter bottom is thus a function of their concentration, size, shape, and density. The settling velocity of a given size particle can be calculated from Stokes' Law, at least for spherical particles. The noble metals tend to be present as spherical particles, whereas the spinels are roughly cubical, so Stokes' Law is appropriate.

Assuming, then, that sludge particles will be present, the issue is to keep them from accumulating in sufficient depth and concentration to shortcircuit the electrodes. This problem can be handled through melter designs which assume the presence of sludge particles and make provisions for the sludge particles to be swept out with the processed glass. For instance, a sloping melter floor with the drain located at the lowest point on the slope may be a possible method for dealing with sludges. Turbulence-producing devices such as bubblers could materially assist the entrainment of the particles in the glass, so that they never settle. Bubblers are also likely to increase the melting rate, and could be readily added. 
The slow rate of sludge accumulation has made this problem difficult to address in melter development and testing. Melter campaigns are sufficiently expensive that it has not seemed justified to operate a melter over several months' time just to check for sludge accumulation. The current West Valley melter design makes some special provisions for the avoidance of sludge accumulation, but only time will tell whether this potential problem will eventually surface (or sink, as the case may be). In the event that sludges cause problems at West Valley, the remedies above are possible ways of dealing with the problem, although at the cost of some design changes in the melter. 


\section{PROCESS CONTROLS}

A complete description of process controls for the joule-heated melter are beyond the scope of this report; a brief description may be found in Siemens et al. (1985). Redox controls for the purpose of avoiding foaming incidents were investigated as part of the work being reported here. The term "redox control" implies a control loop, where real-time information on the redox state of a glass is used as input for melter feed changes to maintain the redox state of the melter glass in some specified range. Obtaining real-time information on the redox state of the glass is very difficult, and at this writing there is no proven way to do this for nuclear waste glass compositions.

Redox control of more ordinary glasses has been accomplished, usually by using an electrochemical oxygen monitor of some sort. The most common electrochemical oxygen meter is based on the use of calcia-stabilized zirconia, which is an ionic conductor for oxygen. By using a closed-ended impermeable tube of this ceramic provided with suitable electrodes, an electromotive force is generated which is related to the oxygen activity difference between the inside and outside of the tube. These tubes have been used for some years and are described in Tran and Brungs (1980). In practice, the zirconia tube is dipped into the glass and air is allowed to contact the inner surface as a reference gas. In some tests conducted at PNL, however, the calcia-stabilized zirconia tube was found to be penetrated at the grain boundaries by typical borosilicate waste glass in a matter of a few days.

Another oxygen-permeable electrode of greater stability is needed. Thoria doped with yttria is an ionic conductor for oxygen which is known to be very thermodynamically stable, and so should not be readily soluble in glass. Though use of thoria-yttria tubes has not yet been evaluated, this approach probably offers the best hope for real-time monitoring.

Several non-real-time methods have been evaluated for measuring the redox state of nuclear waste glasses, including wet chemistry, colorimetry, Mossbauer spectroscopy, and ion chromatography. Because these methods are not real-time, the redox state information they could provide would be delayed, at best, 4 to 8 hours from sample recovery. Availability of the data would then permit 
adjustment of the reductant content of the feed to the melter. These methods are all based on use of the ferrous/ferric iron ratio as an index to redox state, and thus assume an oxygen partial pressure in the range 10E-2 to $10 \mathrm{E}-8$ atmospheres, which is applicable to present nuclear waste glasses. Other multivalent metals similar to iron are available to cover other redox ranges should compositions change greatly, but the methods described below may not be as applicable to those metals, or their usefulness ranking may change.

\section{Wet Chemistry}

A compleximetric, colorimetric procedure developed for the glass industry by Jones, Jansheski, and Goldman (1981) was investigated for its own sake and also for use as a standard for comparison with all of the other methods of measuring the redox potential.

The method has several important advantages. First, the use of phenanthroline makes it specific for iron, unlike the earlier titrimetric methods (e.g., Close and Tillman 1969) that remain prevalent in the glass industry today. Second, only one acid digestion is required. The ferrous iron initially released forms an orange-colored complex with 1,10-phenanthroline for a direct measurement of the ferrous iron concentration. The total iron concentration is then measured by reducing the remaining ferric iron in solution with hydroquinone. The ferric iron content of the glass is then determined by the difference in these measured quantities.

The third advantage of the method is that it was developed to be conducted without the need of an inert atmosphere during sample digestion. This was tested by digesting a sample in air and in ultra-high-purity argon. The results presented in Table 8 show no effect from the surrounding atmosphere, at a confidence level of $99 \%$. Fourth, the procedure is rapid and easy to perform, with excellent reproducibility. The average error on a ferrous-to-total iron (FTI) ratio is generally less than $4 \%$ for the $20 \mathrm{mg}$ of glass used for each sample. The minimum detection limit for ferrous iron for this method is approximately $0.005 \mathrm{wt} \% \mathrm{Fe}$. Given that most glasses considered here have greater than 5 wt\% Fe as total iron, the minimum ferrous/ferric iron ratio that 
TABLE 8. Wet-Chemistry Analysis Results for West Valley Glass Ferrous/Ferric Iron Ratios Showing Negligible Atmosphere Effect over Four Runs

\begin{tabular}{lllll} 
& Run \# & & \multicolumn{2}{c}{ Surrounding Atmosphere } \\
\cline { 2 - 4 } & $\frac{\text { Air }}{1}$ & & $1.25(\mathrm{a})$ & $\frac{\text { Argon }}{1.27}$ \\
2 & 3 & 1.21 & 1.28 \\
& 4 & 1.19 & 1.26 \\
Average & & 1.21 & 1.17 \\
Standard deviation & & 1.22 & 1.24 \\
& & 0.05 & 0.03
\end{tabular}

(a) Values are ratio of ferrous Fe/ferric Fe, so they are unitless.

can be measured is about 0.001 . Thus, sufficient analytical sensitivity is available to analyze any sample that could produce a detectable ferrous peak in a Mossbauer spectrum.

Colorimetry

The analysis of glass color is another way of characterizing the redox state of waste glasses. Many apparently black materials exhibit colors when observed in powdered form, as exemplified by the field geologist and his "streak plate," a slightly rough piece of alumina across which a sample is drawn so that it leaves a mark composed of fine powder. Glasses lacking ferrous iron generally exhibited a light tan color when ground to a fine powder, whereas glasses with a measurable ferrous/ferric ratio were gray and became darker with larger ratios. This observation was less well-defined as the chromium content of the glass increased. The color change was readily observable for the WV-199 composition containing $0.22 \mathrm{wt} \% \mathrm{Cr}_{2} \mathrm{O}_{3}$ but was difficult to detect for the WV-182 composition containing 0.66 wt\% $\mathrm{Cr}_{2} \mathrm{O}_{3}$. There is no visible change in color in Hanford glass that contains greater than $1 \% \mathrm{Cr}_{2} \mathrm{O}_{3}$. If the color of a glass powder is measured instrumentally, it might be possible to correlate with the oxidation state of the glass. If colorimetry 
is viable, adaptation to the hot-cell environment, by using video cameras and optical fibers to lessen radiation effects, is somewhat easier than other methods.

A brief discussion of colorimetry is required before discussing the results. Color analysis is heavily used in industry for quality control, mixing of pigments, etc. Computerized commercial colorimeters are available for most applications. Highly absorbing nuclear waste glasses will have their own characteristic reflectance spectrum over a wavelength range of 380 to $780 \mathrm{~nm}(0.38$ to $0.78 \mathrm{\mu m})$, which covers the entire visible spectrum. The reflectance value at each wavelength is then multiplied by a standardized value for the selected illuminant source, from published tables. This product, at each wavelength, is then multiplied by the published $x^{\prime}, y^{\prime}$, or $z^{\prime}$ tristimulus values, each representing an internationally accepted primary visual stimulus (e.g., for green, blue, and red, respectively). The products of these multiplications at each wavelength are summed over the wavelength range specified above to arrive at values $X, Y$, and $Z$ which describe the object's color in numerical terms.

In tests conducted at PNL, finely ground glass waste powders were characterized for their ferrous/ferric ratio using wet chemistry and then packed into small glass vials. A reflectance spectrum was taken over a 380 - to $780-\mathrm{nm}$ range at $10-n m$ intervals using a diffuse reflectance-integrating sphere coated with barium sulphate in a Beckman spectrometer. Appropriate black and white standards were used as the $0 \%$ and $100 \%$ reflectance values. The chromacity values were determined as described above. It is felt that reproducibility could be significantly improved if the powders were pressed into selfsupporting discs rather than packed into vials.

Results for two West Valley compositions are presented in Figure 11, in which spectral purity is compared against the ferrous/ferric ratio. The low chromium content in WV-199 causes a strong decrease in spectral purity as the ferrous/ferric ratio increases to a value near 0.5 , and then a relatively flat trend for more reduced samples. The relevant $\mathrm{Fe}^{+2} / \mathrm{Fe}^{+3}$ ratio is 0.2 to 0.3 , so the spectral purity change in low-chromium glasses is most rapid in the desired range. 

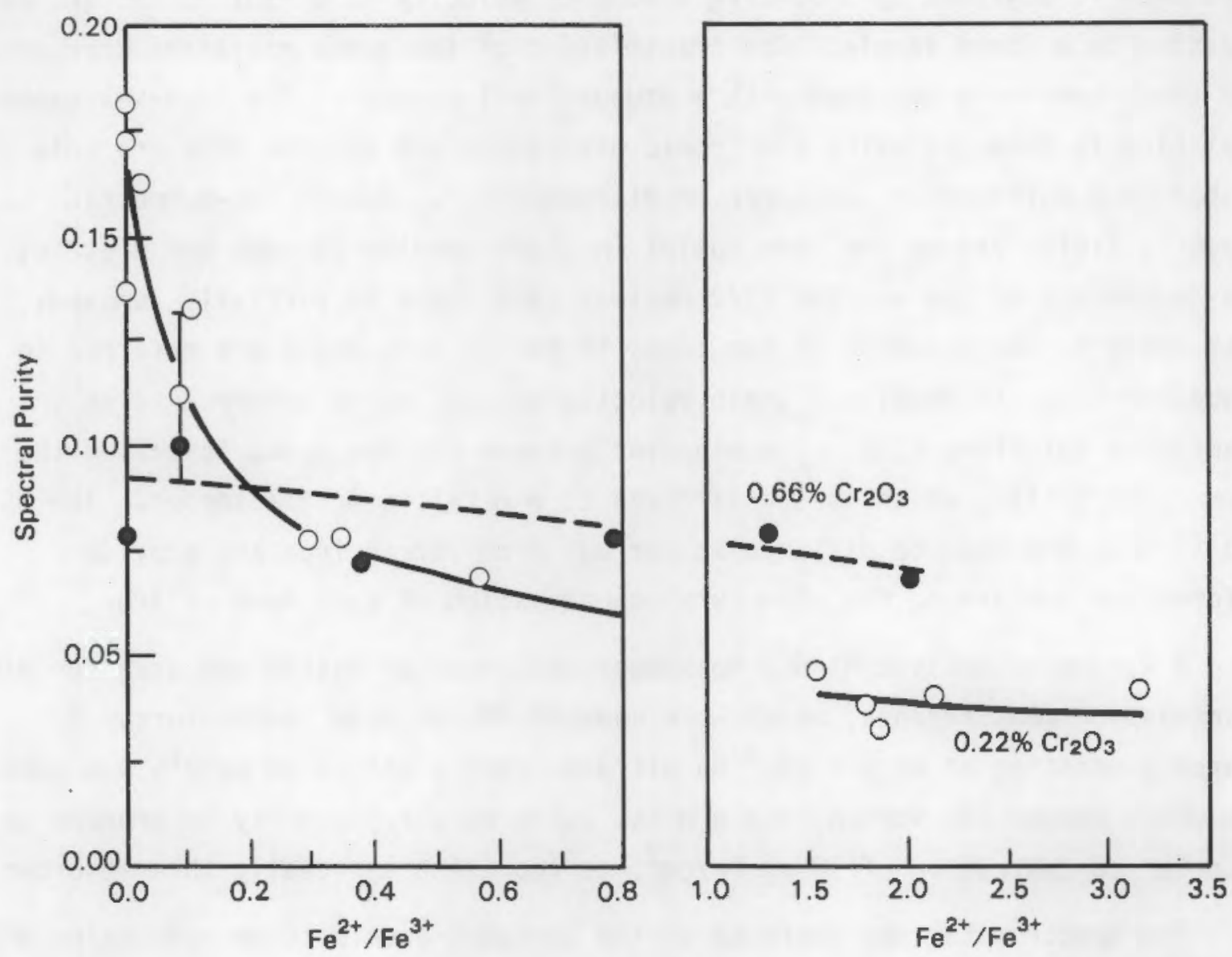

FIGURE 11. Spectral Purity, as Measured on West Valley Glass Powders, Compared to the Ferrous/Ferric Iron Ratio

As seen from the data on a higher-chromium-containing waste glass in Figure 11, the additional chromium obscures the trend described above, making this approach unsuitable for high-chromium wastes. The present reference composition, WV-205, has only 0.14 wt\% $\mathrm{Cr}_{2} \mathrm{O}_{3}$ so colorimetry should be appropriate. Further work should be done on the effect of chromium content close to the nominal composition; these results could then be coupled with the batch analysis, which is to be used heavily at West Valley, so that the chromium effect can be accounted for.

Mossbauer Spectroscopy

The ${ }^{57} \mathrm{Fe}$ Mossbaver spectroscopy is a nuclear resonance technique that involves the recoilless emission and absorption of $14.4-\mathrm{keV}$ gamma radiation. 
Resonance is achieved by imparting a Doppler velocity to a radioactive source relative to a fixed sample. The transmission of the gamma radiation through the glass sample is measured with a proportional counter. The 14.4-keV gamma radiation is selected using electronic discriminators and the data are collected in a multichannel analyzer or microcomputer. Due to non-symmetric electric fields around the iron nuclei in glass samples at room temperature, the degeneracy of the excited $\pm 3 / 2$ nuclear spin state is partially removed. This leads to the presence of two peaks in the spectra which are referred to as a quadrupole-split doublet. Their velocity separation is referred to as the quadrupole splitting (QS). The midpoint between the two peaks is called the isomer shift (IS), which is standardized to a metallic iron absorber. The QS and IS data are used to distinguish ferrous from ferric iron and provide information concerning the structural coordination of each form of iron.

A Ranger Scientific MS-900 Mossbauer spectrometer system was used for all transmission measurements, which were made at PNL at room temperature. A source consisting of $60 \mu \mathrm{Ci}$ of ${ }^{57} \mathrm{Co}$ diffused into a palladium matrix was used. The glass powder was formed into a disk, using an acrylic spray to produce an absorber concentration of $10 \mathrm{mg} \mathrm{Fe} / \mathrm{cm}^{2}$, to represent an ideally thin absorber.

The spectrometer was operated in the constant-acceleration mode using a saw-tooth waveform to drive the velocity transducer at an increment of about $0.009 \mathrm{~mm} / \mathrm{s}$-channel. Interferometry data were collected in 1024 channels of memory; this process was slow, typically requiring 6 to 20 hours. Analysis of the resulting curve shapes was equally tedious, requiring a substantial amount. of computerized analysis to determine the Lorentzian and Gaussian components in the lineshape representing the data. The procedure is very involved, and is still only an approximation.

The Mossbauer technique was used on several nonradioactive waste glasses produced under conditions yielding several different ferrous/ferric iron ratios, and was found to produce satisfactory correlations with wet chemistry. The combination of the long data acquisition time and the lengthy analysis make the Mossbauer analysis impractical for on-line redox control of nuclear waste glasses. 
Because the range of acceptable ferrous/ferric iron ratios for the vitrification process is estimated to be between 0.1 and 0.5 , it is possible to simply use the intensity ratio of high-velocity ferrous and ferric peaks. With this simplification, intensities need only be measured at three velocity locations. The data acquisition time is grossly shortened, as is the numerical analysis. Using this approach and faster counting electronics, it was estimated that analytical results could be obtained in less than an hour. Thus the Mossbauer approach appeared to be a useful tool, and a shielded container was built for radioactive trials. However, subsequent analyses conducted with radioactive waste glasses containing ${ }^{90} \mathrm{Sr}$ and ${ }^{137} \mathrm{Cs}$ were unsuccessful, presumably due to background radiation caused by the samples. Because of this problem, the Mossbauer technique is considered unusable for measuring nuclear waste glass redox states.

Ion Chromatography

Ion chromatography is a promising technique for measuring ferrous/ferric iron ratio, and so its applicability to the present problem was investigated. The feasibility determination was done by PNL staff at the Dionex Corporation facility at Sunnyvale, California. The equipment consisted of a 2000 series ion chromatograph with a post-column reactor and a ultra violet/visible light detector option. The analytical column was an HIC-CS5.

Ion chromatography is similar to conventional liquid chromatography in that ions in solution are pumped through a column where the ions are retained to slightly differing extents and thus travel at different speeds. The detector is designed to detect any ion that may be in solution, and thus a chromatogram is produced which consists of the arrival time of these various ions.

Using the Dionex equipment on WV-202 glass, which is used at PNL as an internal standard for ferrous/ferric iron ratio, the detection limit was determined to be $0.1 \mathrm{ppm}$ for ferrous iron. This detection limit was obtained in the presence of 20 ppm ferric iron without any interference, which would correspond to a ferrous/ferric ratio of 0.005 . This lower limit is ample in light of present specifications, which are in the range of 0.2 to 0.3 ferrous/ferric iron ratio. 
During PNL's evaluation of the equipment, it was determined that the solution preparation procedure itself could be simplified, eliminating the need for an oxygen-free atmosphere. The modified procedure is as follows:

- Add $0.5 \mathrm{ml}$ sulfuric acid, mix with powder.

- Add $1.5 \mathrm{~mL}$ hydrofiuoric acid; mix.

- Add $25 \mathrm{~mL} 4 \%$ boric acid.

- Add $10 \mathrm{~mL}$ potassium hydrogen phosphate and $2 \mathrm{~mL}$ ammonium hydroxide.

- Transfer to volumetric flask and dilute to volume.

- Analyze by ion chromatography.

Thus, ion chromatography appears to be an applicable method for measuring the ferrous/ferric iron ratio of nuclear waste glasses, since it involves no detectors that are especially sensitive to radiation.

A more detailed description of these redox analysis methods is presented in Goldman (1985). 


\section{COMPUTER AIDS TO PROCESSING}

During the course of the work done at PNL on behalf of the West Valley project, two computer codes, PREDICT and BATCHER, were developed that could be of considerable use as production tools. These two codes are explained in greater detail below. Users' guides were written for both codes by $C$. A. LoPresti of PNL. (a) BATCHER has since been updated in a code called RECIPE (Faletti et al. 1988).

\section{PREDICT}

This program can be used to determine the amounts and composition of a batch of glass-forming oxides to add to a THOREX-zeolite loaded waste mix to build a glass that will meet glass property specifications according to the PNL predictive models.

In terms of general processing, the program receives an Inductively Coupled Plasma--Atomic Absorption (ICP) analysis of the waste mix in terms of ion concentrations. It converts this composition to equivalent oxide weightpercents for a set of oxides contained in its tables. It then pools the oxides into the components required by the glass prediction models, and sets up a trial combined glass composition. It checks this composition against the component space assumptions required by the prediction models. The program then allows the user to adjust the composition of the trial glass through a menu of options until the predicted properties arrive at satisfactory values for a given composition.

The program can be operated either by entering commands interactively through a terminal, or (for batch runs) by providing a command disk file containing the program commands. The input waste mix composition may be input to the program either directly in interactive mode, or through a disk file in either interactive or batch mode.

(a) The users' guides are not publicly available at this time. 
The program also provides for computation of the amounts of sources of the required glass-forming oxides to add to a given weight of the waste mix. This capability is provided by the BATCHER module. This module is implemented as subroutine BATCHER in PREDICT.

\section{BATCHER}

The BATCHER module provides the capability for calculating the amounts of glass-forming source substances to mix with a given amount of waste mix to get a final melt containing oxides in specified proportions to meet glass property requi rements.

The BATCHER module is implemented as a subroutine in the PREDICT Program. It may be invoked in two ways:

1. As a menu item in PREDICT--Once a former's batch composition has been obtained through the properties prediction process, the program allows the user to obtain the amounts of source substances required to make up any amount of the former's batch.

2. Immediately upon entry into the PREDICT Program--This allows the user to determine a batch composition for any formers mix without performing the properties prediction. The user must directly enter the glass formers' composition weight-percents, and the waste mix loading.

In the way of overview, the BATCHER program receives a 1 ist of oxides that represent the extra glass forming oxides to add to the waste mix, as calculated by the PREDICT program. The weight percents of these oxides are expected to be normalized to $100 \%$. The waste mix loading is also required as an input parameter. The user will provide the amount of waste mix oxides to be processed in mass units such as kjlograms. The program will use this information to compute the amounts of each oxide which the sources must provide for the glass to meet the final specification, given the following information:

- the amounts of source substances actually available

- the proportions of oxide(s) each source substance provides. 
The program will query the user for candidate source substances which will each provide some of the oxides. The program will then compute the amounts of given oxides each source substance provides and increment the cumulative anount for each oxide. The program will allow the user to either accept the current candidate source mix or abandon it to try another, until all oxide requirements are met or the user terminates the process.

Nuclear waste glasses are certainly some of the most complex glasses ever made, and the effect of the many possible chemical variations is not well known. The PREDICT program provides an ability to cope with day-to-day variations and, more importantly, to know the probable effects of small variations from nominal compositions. Use of the program in a particular case is easily documented which could be invaluable in an instance where some slight process shift was made to accommodate some change in the waste stream. This is particularly true in the case of West Valley, where little or no actual waste glass sampling is planned, and thus where rigid control of the chemicals being processed is a major emphasis of the control philosophy.

BATCHER is essentially a replacement for the paper-and-pencil spread sheet work that glass formulators have used for many years. Use of the program will eliminate much of the tedium that use of the traditional method would involve for such complex glasses, as well as decreasing human errors. By coupling BATCHER with the PREDICT program, a package has been made available that should permit the West valley vitrification effort to proceed with a minimum of errors.

Although BATCHER and PREDICT were extensively used at PNL and were transferred to West Valley for use there, they were not documented in a referenceable manner. Later refinements on BATCHER led to the computer code RECIPE, which has been documented by D. W. Faletti and others at PNL (1988). 


\section{CONCLUSIONS AND RECOMMENDATIONS}

The following conclusions and recommendations are made based on the testing done by PNL in support of the West Valley waste glass development.

- The computer model resulting from the statistically designed mixture study was very usefui as a means of quickly designing candidate glasses in the face of changing waste stream compositions.

- Foaming of West Valley glasses is most likely caused by oxygen released by jron in the glass, and may be prevented by adding reductants to the feed stream.

- Several methods for evaluating the redox state of the waste glass resulting from a given feed stream were evaluated, but at present the best method is to make a few trial melts containing various reductant levels and measure the ferrous/ferric iron ratio of the resulting glass. There is at present no real-time method for knowing the redox state of a waste glass; use of a solid electrolyte of the proper composition seems a fruitful approach but has not been tested.

- Surface scums resulting from formation of immiscible phases are an impediment to processing as a result of increased viscosity of the top zone, but can be controlled through composition modifications.

- Dense conductive sludges can result in electrical short-circuiting in some melter designs, but effects can be avoided through designs which address this possibility. This issue is one that will only emerge after long periods of continuous processing, and so is relatively undefined at present for the West Valley case. Suitable sampling and analysis should be carried out during the first few months of operation at West Valley in anticipation of possible problems.

- Leach testing of the recommended West Valley glass composition, WV-205 and evaluation of the results by the latest techniques indicates that its resistance to leaching by water is at least as good as SRL-165 glass, and probably better. 


\section{REFERENCES}

Chick, L. A., W. M. Bowen, R. 0. Lokken, J. W. Wald, L. R. Bunnell, and

D. M. Strachan. 1984. West Valley High-Level Nuclear Waste Glass Development: A Statistically Designed Mixture Study. PNL-4992, Pacific Northwest Laboratory, Richland, Washington.

Close, W. P., and J.F. Tillman. 1969. "Chemical Analysis of Some Elements in Oxidation-Reduction Equilibria in Silicate Glasses." Glass Technol. $10(5): 134-146$.

Faletti, D. W., H. Harty, T. A. Erb, and C. A. LoPresti. 1988. User's Guide for West Valley Feed Preparation Code (RECIPE), PNL-6425, Pacific Northwest Laboratory, Richland, Washington.

Goldman, D. S. 1985. Investigation of Potential Analytical Methods for Redox Control of the Vitrification Process. PNL-5581, Pacific Northwest Laboratory, Richland, Washington.

Jones, D. R., IV, W. C. Jansheski, and D. S. Goldman. 1981. "Spectrophotometric Determination of Reduced and Total Iron in Glass with 1, 10 Phenanthroline." Anal. Chem. 53:923-924.

Sasaki, N., M. Karino, H. Okamoto, H. Kashihara, and M. Yamomoto. 1984. "Solidification of the High-Level Liquid Waste from the Tokai Reprocessing Plant." ANS Topical Meeting on Fuel Reprocessing and Waste Management, August 26, Jackson, Wyoming, Vol. 1, pp. 1-147 to 1-160.

Siemens, D. H., W. O. Heath, D. E. Larson, S. N. Craig, D. N. Berger, and R. W. Goldes. 1984. High-Level Radioactive Waste Vitrification Process Equipment Component Testing. PNL-5394, Pacific Northwest Laboratory, Richland, Washington.

Tran, T., and M. P. Brungs. 1980. Physics and Chemistry of Glasses, Vol. 21, No. 5. 


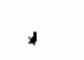

$\checkmark$

.

. 
APPENDIX

LEACH TESTING AND EVALUATION OF WV-205 GLASS FROM

A REPOSITORY PERSPECTIVE 
APPENDIX

LEACH TESTING AND EVALUATION OF WV-205 GLASS FROM

A REPOSITORY PERSPECTIVE

by D. M. Strachan

Ouring FY 1985, the Pacific Northwest Laboratory (PNL) actively participated in studies to select a waste glass composition for use at the West valley melter site in upstate New York. The results of these studies led to the recommendation of the WV-205 composition (Eisenstatt 1985), the chemical durability of which has been investigated quite extensively.

The purpose of this report is to compare the durability of the WV-205 glass, prepared under several conditions, with the durability of a Savannah River Plant glass (frit 165 or SRL-165). A comparison of the chemical durability of WV-205, several variants on this composition, and other waste glasses was needed but had not yet been made. At the request of West Valley Nuclear Services, PNL reviewed the existing chemical durability data (both published and unpublished) and prepared this report.

Four WV-205 glass samples were prepared in the study that led to the selection of this glass for use at West Valley. Two glasses were prepared in the laboratory using conventional methods and chemicals: WV-205 and WV-205A.01. The difference between these two glasses was that the potassium was removed from the WV-205 composition to make the glass WV-205A.01. A third glass sample with the nominal WV-205 composition was prepared in an experimental ceramic meiter and designated ECM85-13. The fourth glass with the nominal WV-205 composition in this study was prepared in a pilot-scale melter and designated PSCM-21. These glasses will be compared in this report with the durability of a sample of SRL-165 which was prepared at PNL; the composition of SRL-165 is shown in Table A.1.

In addition to the composition, there is some indication that the redox state under which a glass was produced may have an effect on its chemical 
TABLE A.1. Composition of Glasses Used in Leach Test Evaluation

\begin{tabular}{lc} 
Oxide & wt\% \\
\hline $\mathrm{Al}_{2} \mathrm{O}_{3}$ & $4.8 \mathrm{~B}$ \\
$\mathrm{~B}_{2} \mathrm{O}_{3}$ & 7.12 \\
$\mathrm{BaO}$ & 0.11 \\
$\mathrm{CaO}$ & 0.97 \\
$\mathrm{CeO}_{2}$ & 0.12 \\
$\mathrm{Cr}_{2} \mathrm{O}_{3}$ & 0.14 \\
$\mathrm{Cs}_{2} \mathrm{O}$ & 0.00 \\
$\mathrm{CuO}$ & 0.06 \\
$\mathrm{Fe}_{2} \mathrm{O}_{3}$ & 10.8 \\
$\mathrm{~K}_{2} \mathrm{O}$ & 0.09 \\
$\mathrm{La}_{2} \mathrm{O}_{3}$ & 1.1 \\
$\mathrm{Li}_{2} \mathrm{O}_{3}$ & 5.05 \\
$\mathrm{MgO}$ & 0.75 \\
$\mathrm{MnO}_{2}$ & 3.3 \\
$\mathrm{Na}_{2} \mathrm{O}$ & 10.9 \\
$\mathrm{Nd}_{2} \mathrm{O}_{3}$ & 0.60 \\
$\mathrm{NiO}_{1} \mathrm{O}_{2}$ & 0.85 \\
$\mathrm{P}_{2} \mathrm{O}_{5}$ & 0.03 \\
$\mathrm{PbO}^{20}$ & 0.11 \\
$\mathrm{RuO}_{2}$ & 0.10 \\
$\mathrm{SiO}_{2}$ & 51.36 \\
$\mathrm{SO}_{3}$ & 0.29 \\
$\mathrm{SrO}_{\mathrm{ZnO}}$ & 0.03 \\
$\mathrm{ZnO}_{\mathrm{ZrO}}$ & 0.27 \\
$\mathrm{Total}_{2}$ & 1.52 \\
\hline & 100.37
\end{tabular}

durability. Two of the glasses examined in this study were produced under reducing conditions such that the $\mathrm{Fe}^{++} / \mathrm{Fe}^{+++}$ratio was between 0.2 and 0.3 in the solid glass. These two glasses were ECM85-13 and SRL-165. The remaining glasses were oxidized, with the $\mathrm{Fe}^{++} / \mathrm{Fe}^{+++}$ratio equal to 0.004 or less. 
ANALYSIS OF THE DATA

To understand the rate of attack by water on the glass matrix it is necessary to look at the data for an element that does not precipitate as an insoluble mineral, either on the surface of the glass or at some other point in the leach vessel. Boron, a component in most nuclear waste glasses, is one such element that is very soluble at temperatures relevant to leaching. Boron also remains soluble when the leachant contains significant concentrations of other ions dissolved from the glass. Therefore, by looking at the boron results, one can obtain a good understanding of the glass behavior.

Figure A.l shows the results of plotting the normalized boron concentrations for the glasses used in this analysis. The normalized boron concentration is the concentration in $\mathrm{mg} / \mathrm{L}$ divided by the mass fraction of boron in the glass. Use of the normalized concentration allows the solution results from glasses of different compositions, including boron content, to be compared. In this plot, data from 3-d to 56-d monolith (MCC-1) tests and 7-d to 56-d powder (MCC-3) tests are plotted.

To reconcile the different surface areas between the monolith tests and the powder tests, the time for the powder tests was recalculated to be equivalent to the time for the monolith tests. That is, specimens which have different surface areas (S) will yield equivalent data when they have been tested such that the ratios $(S \cdot t) / V$ are equal ( $V$ is the solution volume). This is an indication that the rate of dissolution of the glass is a function of the concentration in solution of species released from the glass, rather than a direct function of time, and is the basis for extrapolating from behavior in a static leach test to behavior in a repository. Thus, the "time" which is used in Figure $A .1$ is real for the monolith tests $\left[S / V=10 \mathrm{~m}^{-1}\right]$, but recalculated for the powder tests to take into account the acceleration factor, i.e., the ratio $[(s \cdot t) / V]$ for the powder test times $\left[10 m^{-1}\right]$. For example, in one of the powder tests a $S / V$ ratio of $2000 \mathrm{~m}^{-1}$ was used in an experiment that lasted $28 \mathrm{~d}$ $\left[(s \cdot t) / V=56000 \mathrm{dxm}^{-1}\right]$. This data point was plotted at $5600 \mathrm{~d}$ in Figure A.1, which would be the equivalent of performing an MCC-1 experiment at $S / \mathrm{V}=10 \mathrm{~m}^{-1}$ for $5600 \mathrm{~d}$. 


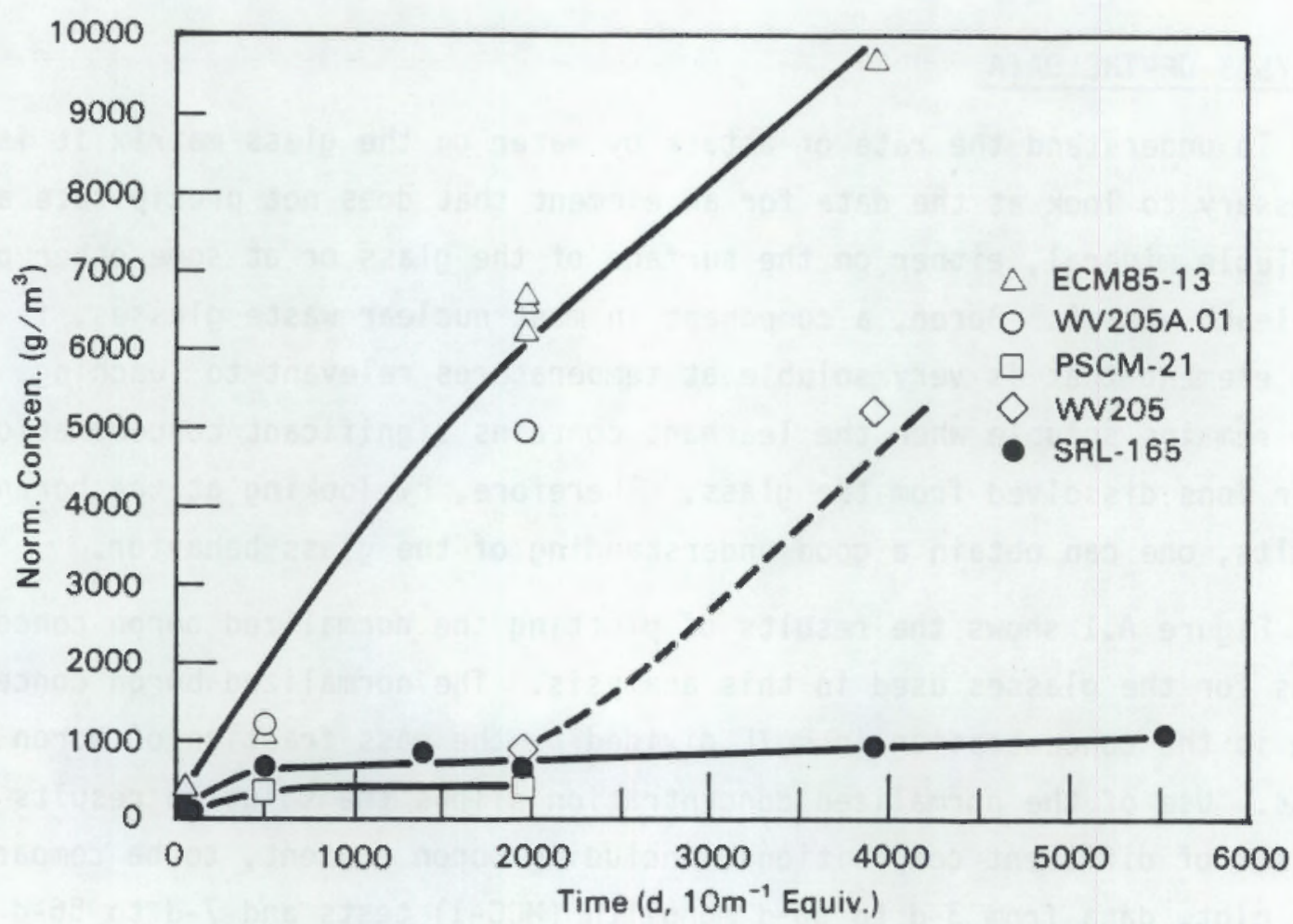

FIGURE A.1. Normalized Boron Concentrations in Solution as a Function of Leach Time, Plotted to Normalize Surface Area Effects

Because most of the data on such a plot as Figure A.1 are squeezed into the lower left corner, there are not many visible data that one can use to obtain an understanding of the glass behavior and, hence, a meaningful comparison is difficult if not impossible. More data may be made visible by plotting the data on a "log-log" plot. However, the mathematical relationship which one is familiar with in a linear plot becomes distorted. The same data that are plotted in Figure $A .1$ have been replotted in a plot of the log of the normalized concentration vs. the log of time (Figure A.2). This plot can be understood by considering what happens at the beginning of glass dissolution and after a long time.

At both ends of the dissolution curve there are linear portions where the dissolution rate $\left(k_{+}\right)$is independent of time. At early times, the glass dissolves with a forward dissolution rate because there is nothing in solution to impede the dissolution process. After a very long time, the glass dissolves again at a constant rate $\left(k^{\infty}\right)$ when the alteration processes have reached a 


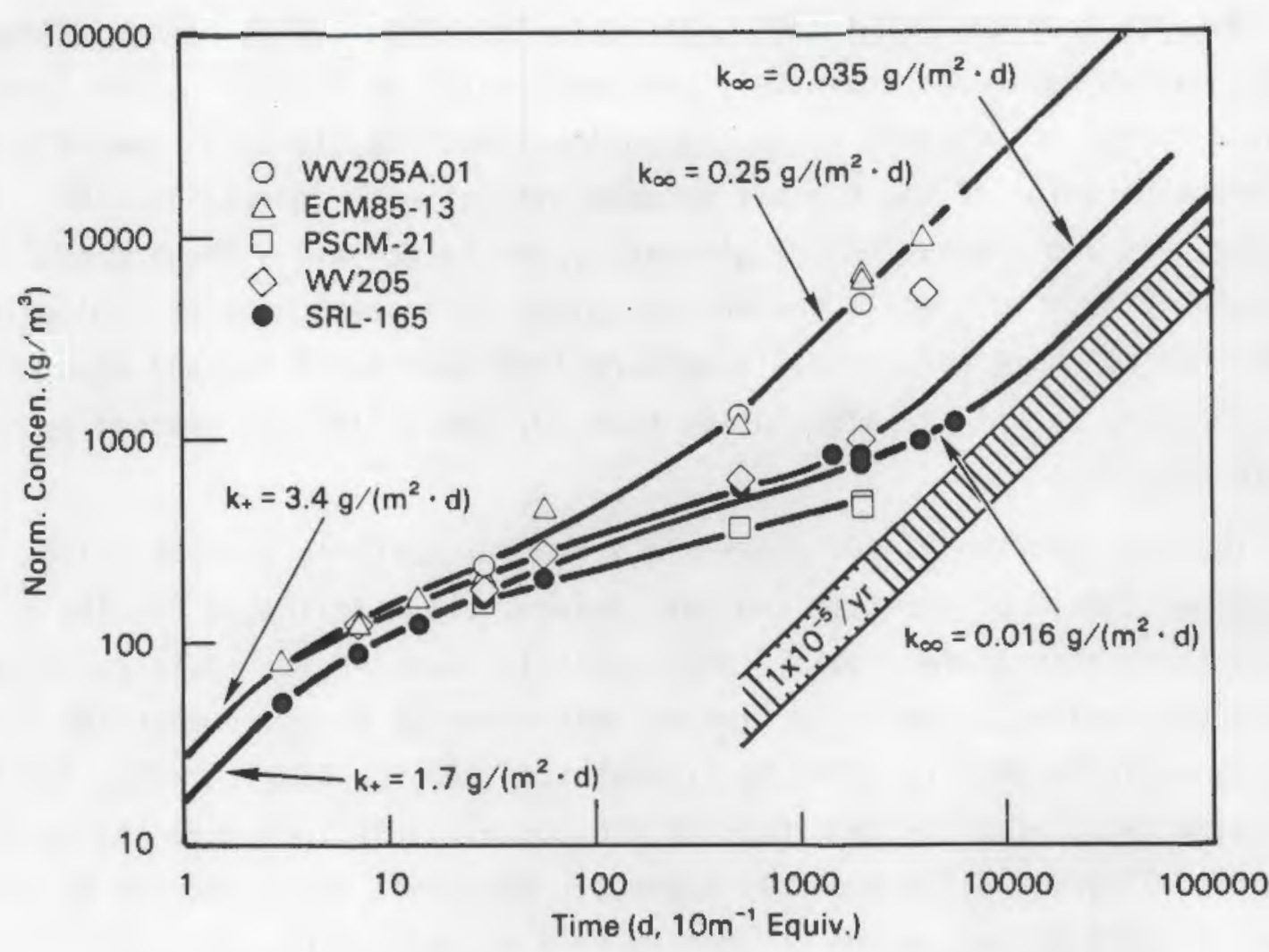

FIGURE A.2. Replot of Figure A.1, with Log-Scale Axis for Analysis Purposes

steady rate. Both rates are time and $S / V$ ratio invariant. When one considers the general formula for a straight line, $y=m x+b$, a "log-log" plot changes the relationship to one with unit slope; namely, $\log (y)=\log (m x+b)$. Thus, at the two extremes of the linear plot one expects to find a straight line in a "log-log" plot with unit slope. The portion of the curve in Figure A.1 that lies between the two linear portions becomes a transition between the two straight lines in the "log-log" plot. The rates or slopes of the curve in Figure A.1, which correspond to the forward reaction rate (early time) and the final rate (very long time or high $[(S \times t) / V]$ become intercepts of the straight lines in Figure A.2 at a time of one day; in this case the ordinate.

With that explanation of the "log-log" plot, a meaningful comparison of the glasses may be made. Figure A.2 shows that the forward reaction rates of the west Valley glasses are about equal to each other, $3.4 \mathrm{~g} /\left(\mathrm{m}^{2} \mathrm{~d}\right)$, and about a factor of 2 greater than that of SRL-165, $1.7 \mathrm{~g} /\left(\mathrm{m}^{2} \mathrm{~d}\right)$. 
Results from the MCC-1 tests, the data less than $100 \mathrm{~d}$, indicate that all three glasses behave approximately the same, with the ECM85-13 glass dissolving about a factor of two more at $56 \mathrm{~d}$ than the remaining glasses. However, the different behavior of the glasses becomes evident with increasing time. Both the ECM85-13 and the WV-205A.01 glasses appear to achieve a final dissolution rate of $0.25 \mathrm{~g} /\left(\mathrm{m}^{2} \cdot \mathrm{d}\right)$, while the $S R L-165 \mathrm{glass}$ achieves a rate of $0.016 \mathrm{~g} /\left(\mathrm{m}^{2} \cdot \mathrm{d}\right)$. As another point of reference, it appears from both published and unpublished data that the same final dissolution rate $\left[0.016 \mathrm{~g} /\left(\mathrm{m}^{2} \cdot \mathrm{d}\right)\right]$ is reached by PNL 76-68 glass.

The data for the WV-205 glass are somewhat scattered at high values of equivalent time. Of the last two data points, the triplicated results at $1980 \mathrm{~d}$ (equivalent) are probably more reliable than the last data point at $3920 \mathrm{~d}$ (equivalent). When the line of unit slope is drawn so that the final rate is equal to that reported by Eisenstatt $(1985)\left[0.035 \mathrm{~g} /\left(\mathrm{m}^{2} \cdot \mathrm{d}\right)\right]$, the 1 ine fits quite well with the remainder of the curve. This indicates that a final rate of $0.035 \mathrm{~g} /\left(\mathrm{m}^{2} \cdot \mathrm{d}\right)$ is probably correct. More data would need to be collected in this "time" regime to confirm this extrapolation.

Although data from the PSCM-21 glass have not been collected for a long enough period of time, it would appear that the behavior of the PSCM-21 glass is similar to that of the SRL-165 glass.

From the scatter in the data it is not possible to determine if there is a major effect due to the redox state of the glass. Comparing glasses of the same nominal composition, i.e., WV-205, PSCM-21, and ECM85-13, it would appear that those glasses prepared under an oxidizing atmosphere, i.e. no sugar or formic acid added, reach a lower final dissolution rate than does the glass prepared under reducing conditions. One must, however, recognize that the SRL-165 glass was prepared under reducing conditions, albeit with a different composition.

In a repository, glass will not be contacted instantaneously by a volume of water as it was in the laboratory tests conducted here. The ability of species released from the glass to transport away from the surface of the glass is expected to be very poor. As groundwater reaches the glass, it will essentially become saturated instantaneously, such that the minimum dissolution rate 
will be established from the beginning, and a steady-state dissolution rate will be established that depends on mass transfer behavior in the repository, irrespective of any $S / V$ calculated for the repository environment.

However, to illustrate the significance of Figure A.2, imagine that somehow a cylinder of glass in a repository was instantaneously and uniformly contacted by $1 \mathrm{~L}$ of groundwater, then the $S / V$ would be on the order of 1000 to $10000 \mathrm{~m}^{-1}$, assuming a glass cylinder $0.3 \mathrm{~m}$ in diameter and $3 \mathrm{~m}$ talt, with some increase of surface area due to cracking. Referring to Figure A.2, where the abscissa is computed assuming $S / V=10 \mathrm{~m}^{-1}$, the release shown for $1000 \mathrm{~d}$, for example, would correspond to about 1 to $10 \mathrm{~d}$ in a repository. Hence, even if some groundwater were available immediately to contact the glass, it would saturate very rapidly.

Therefore, the final dissolution rate found at large values of (Sxt)/V in static leach tests, where the solution reaches its maximum saturation with respect to the glass, is the only appropriate value to compare with the NRC's 10CFR60 criterion. The regulatory limit, converted to the equivalent normalized concentration by assuming, again, a glass cylinder $0.3 \mathrm{~m}$ in diameter and $3 \mathrm{~m} \mathrm{tall,} \mathrm{with} \mathrm{some} \mathrm{increase} \mathrm{of} \mathrm{surface} \mathrm{area} \mathrm{due} \mathrm{to} \mathrm{cracking,} \mathrm{is} \mathrm{also} \mathrm{repre-}$ sented on Figure A.2. The final measured dissolution rate of WV-205 glass $\left[0.035 \mathrm{~g} /\left(\mathrm{m}^{2} \cdot \mathrm{d}\right)\right]$ is about 3 to 6 times greater than this limit.

Other elements, such as $\mathrm{Na}, \mathrm{Li}$, and $\mathrm{K}$, in these glasses behave similarly to $B$ until solubility is a controlling factor at very high amounts of dissolved glass. Although Cs data were not collected on all of the solutions, Cs behaves like B during the early periods of glass dissolution. However, later in the $M C C-1$ tests and from the start in the $M C C-3$ tests, the $C s$ data indicate that there is some control by a solid phase or by sorption in the gel layer. The normalized releases for $C s$ in the longest $M C C-3$ tests were, in all cases, a factor of 10 below that for $B$ for the West Valley glasses reported here. No Cs analyses were performed on the solutions from the SRL-165 glass specimens.

Elements such as $\mathrm{Al}, \mathrm{Ca}, \mathrm{Si}$, and Sr show obvious control by solubility or sorption. Examples of these data are shown for SRL-165 and WV-205 glasses (Figures $A .3$ and $A .4$, respectively). The concentrations shown in Figures $A .3$ 


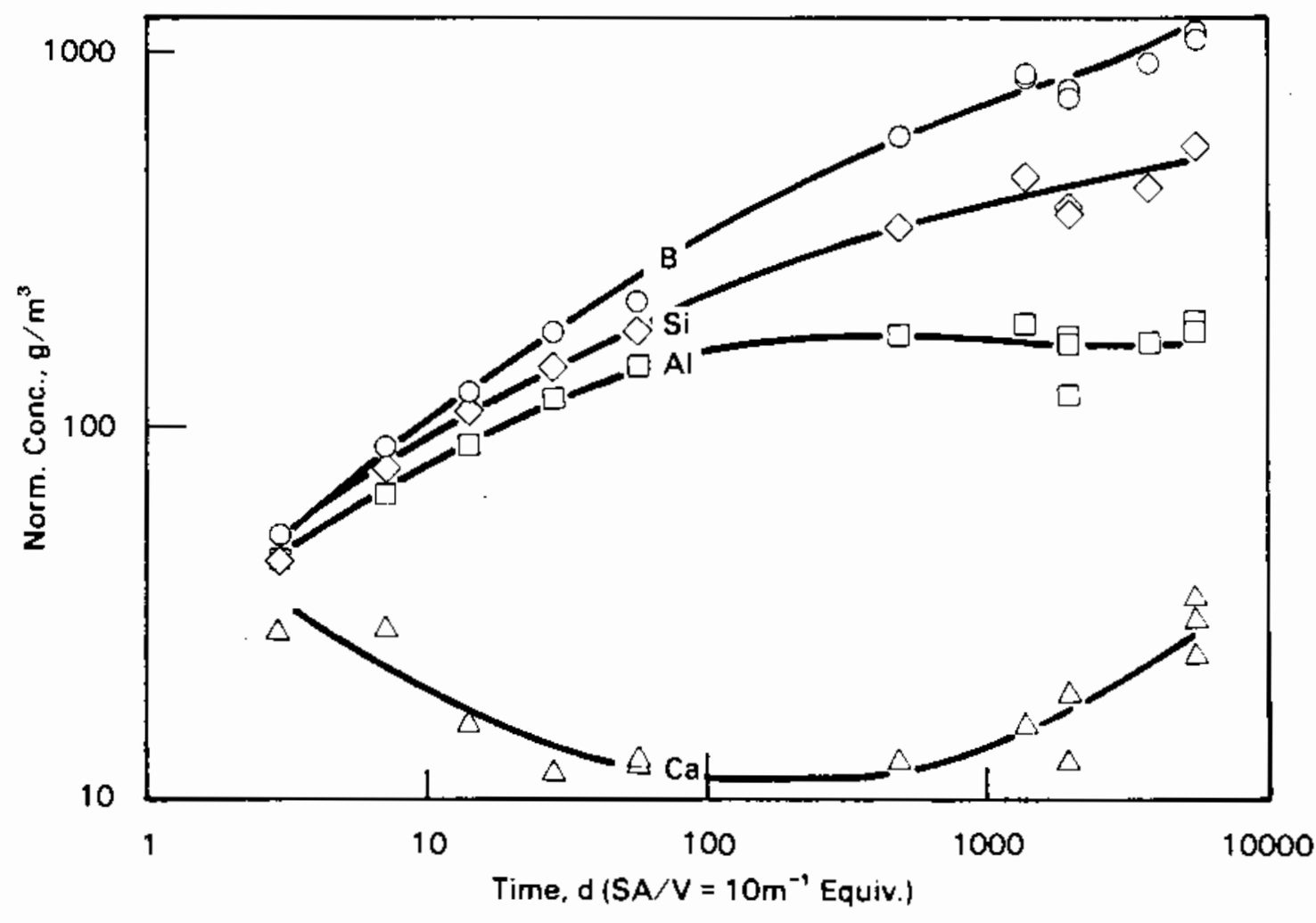

FIGURE A.3. Leaching Data for Several SRL-165 Glass Elements known to be Controlled by Solubility of Sorption

and A.4 are normalized and are, therefore, directly comparable. For most of the radionuclides of interest, such as $U$ and the transuranics, solubility will be a controlling factor at very small amounts of dissolved glass and, hence, will fall quite far below the regulatory limit.

Figure A.5 shows the results from the pH measurements of the solutions. These are the $\mathrm{pH}$ values measured at room temperature after cooling the solutions from $90^{\circ} \mathrm{C}$. With the exception of a few questionable data, the pH values for any of the five glasses lie within 0.5 units of each other with no discernible trend relative to each other within the experimental uncertainty of about $0.3 \mathrm{pH}$ unit. As expected, the $\mathrm{pH}$ increases with increasing glass dissolution (time) because of the general incongruency of the net dissolution reactions involved in which the alkalis are not precipitated. In general, and based on past experience, these solutions would have a pH of about one unit lower when measured at $90^{\circ} \mathrm{C}$ (Grambow and Strachan 1984). 


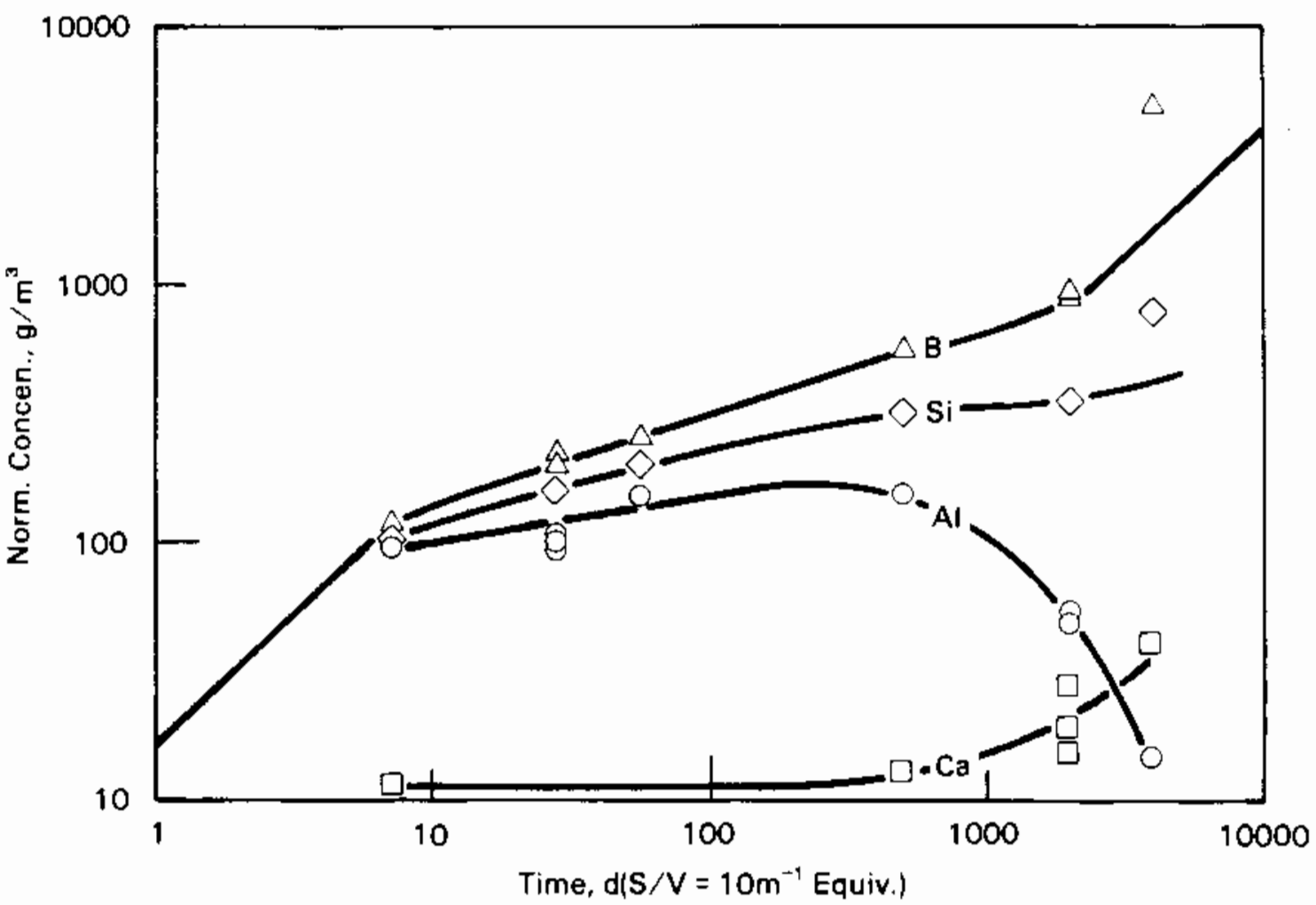

FIGURE A.4. Leaching Data for Several WV-205 Glass Elements Known to be Controlled by Solubility of Sorption

In addition, it must be recognized that the increases in $\mathrm{pH}$ and solution concentrations shown in these figures will not continue unabated. Repository conditions such as groundwater composition, mass transport, and flow rate will impose a practical limit on these increases.

\section{CONCLUSIONS}

From the above analysis the following preliminary conclusions can be made concerning the behavior of the West Valley family of glasses relative to that of SRL-165. From the data available, it would appear that the WV-205 glass has a final dissolution rate of $0.035 \mathrm{~g} /\left(\mathrm{m}^{2} \mathrm{~d}\right)$, or about a factor of two worse than that of SRL-165 glass. The same glass, prepared in the pilot-scale ceramic me1ter, PSCM-21, appears to dissolve at a slightly lower rate than either WV-205 or SRL-165, but insufficient data have been taken to indicate what the final dissolution rate is. Both WV-205A.01 and ECM85-13 appear to have final 


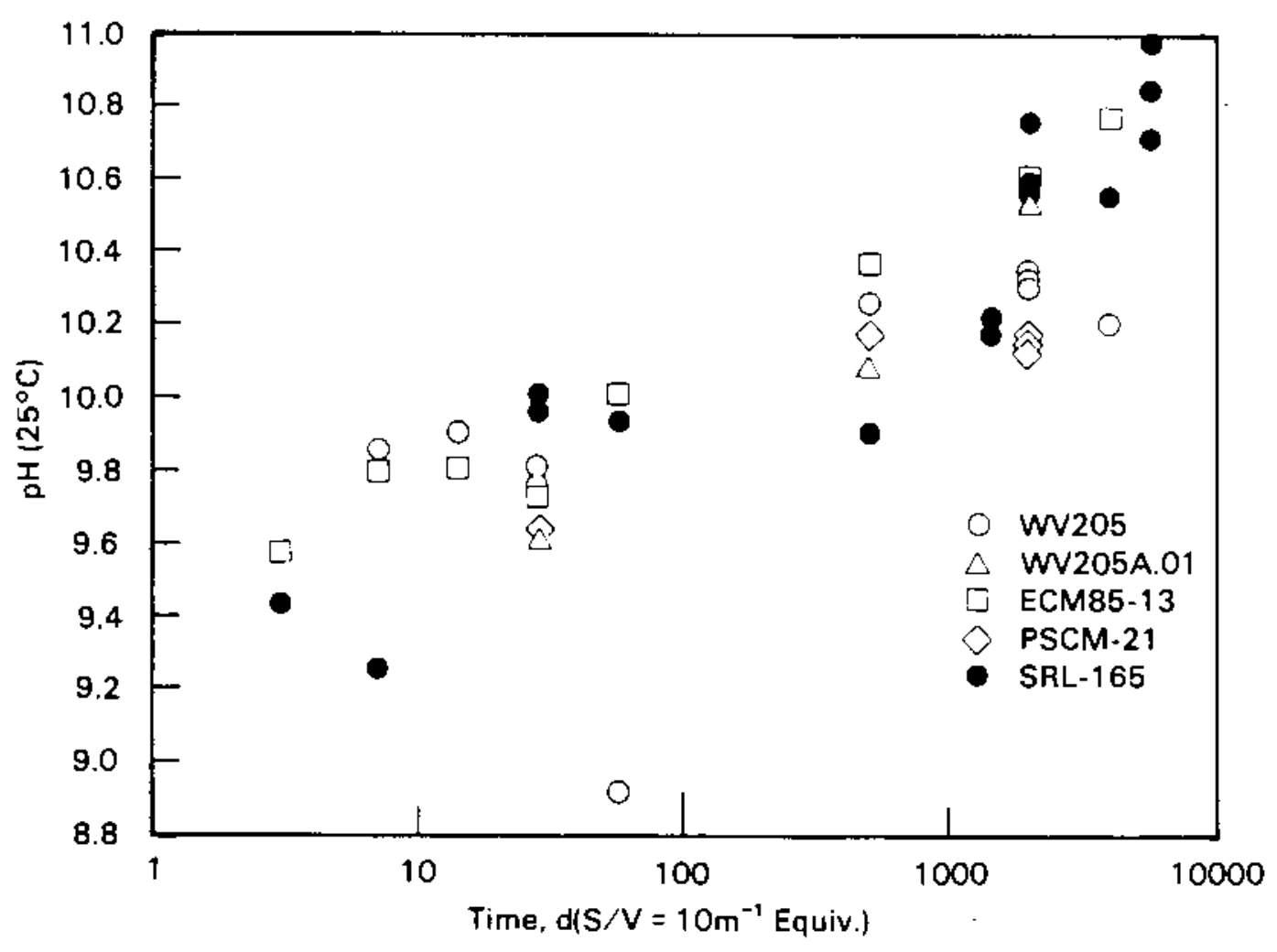

FIGURE A.5. Trends in pH Measurements of the Leach Solutions

dissolution rates that are about an order of magnitude greater than that of SRL-165 glass. A rough analysis of the data indicates that glasses of the same composition, which are prepared under oxidizing conditions, dissolve with a slower rate than those produced under reducing conditions when both are tested under oxidizing conditions. A definitive answer to this question requires additional data that have not previously been collected.

Although somewhat more speculative, it would appear that WV-205, PSCM-21, and SRL-165 glasses have final release rates which approach the one part in $10^{5}$ per year criterion from 10CFR60. The time that these glasses, once placed in a repository, would significantly exceed the criterion would appear to be from $1 \mathrm{~d}$ to $10 \mathrm{~d}$, from the analysis performed here. 


\section{REFERENCES}

Eisenstatt, L. R. 1986. Description of West Valley Demonstration Project Reference High-Level Waste Form and Canister. DOE-NE-44139-26, West VaTley, New York.

Grambow, B. E., and D. M. Strachan. 1984. "Leaching of Nuclear Waste Glasses Under Near-Saturation Conditions." In Scientific Basis for Nuclear Waste Management VII, G. L. McVay, ed., North-Holland, New York. 
i

. 


\section{DISTRIBUTION}

No. of

Copies

OFFSITE

10 DOE Office of Scientific and Technical Information

6 DOE Office of Civilian

Radioactive Waste Management

Forrestal Building

Washington, DC 20575

ATTN: L. H. Barrett, RW-33

C. R. Cooley, RW-40

J. R. Hilley, RW-30

S. H. Kale, RW-20

D. E Shelor, RW-32

R. Stein, RW-23

3 DOE Office of Defense Waste \&

Transportation Management GTN

Washington, DC 20545

ATTN: K. A. Chacey, DP-123

G. H. Daly, DP -124

T. B. Hindman, DP -12

4 DOE Office of Remedial. Action GTN and Waste Technology

Washington, DC 20545

ATTN: J. A. Coleman, NE-24

T. W. McIntosh, NE-24

W. R. Voight, NE-20

H. F. Walter, NE-24

A. T. Clark

Division of Fuel Material Safety

Nuclear Regulatory Commission Washington, DC 20555

V. Stello

Office of the Executive Director for Operations

Mai1 Station 6209

Nuclear. Regulatory Commission Washington, DC 20555
No. of

Copies

\section{S. Meyers}

Environmental Protection Agency

Office of Radiation Programs

ANR -458

401 M Street, S.W.

Washington, DC 20460

J. M. McGough

DOE Albuquerque Operations Office

P. 0. Box 5400

Albuquerque, NM 87185

P. G. Hagan

Joint Intergration Office

Carlmant Executive 1

4308 Carlisle N.E.

Suite 101

A1buquerque, NM 87107

E. Maestas

DOE West Valley Demonstration

Project Office

P.0. Box 191

West Valley, NY 14171

3 DOE Idaho Operations Office

550 Second Street

Idaho Falls, ID 84301

ATTN: C. R. Enos

J. P. Hamric

S. T. Hinschberger

F. T. Fong

DOE San Francisco Operations

1333 Broadway

Oakland, CA 94612

M. R. Jugan

DOE Oak Ridge Operations Office

P.0. Box E

Oak Ridge, TN 37830 
No. of

Copies

H. J. Goldston

DOE Savannah River Operations Office

P.0. Box A

Aiken, SC 29801

M. J. Steindler

Argonne National Laboratory

9700 South Cass Avenue

Argonne, IL 60439

C. S. Abrams

Argonne Nationa 1 Laboratory

P.O. Box 2528

Idaho Falls, ID 83401

3 Battelle Mernorial Institute

Project Management Division $505 \mathrm{King}$ Avenue

Columbus, $\mathrm{OH} 43201$

ATTN: W. A. Carbeiner

R. A. Nathan

Technical Library

L. D. Ramspott

Lawrence Livermore National Laboratory

University of California

P.0. Box 808

Livermore, CA 94550

D. T. Oakley, MS 619

Los Alamos Scientific Laboratory

P.D. Box 1663

Los Alamos, NM 87544

4 Oak Ridge National Laboratory

P.0. Box Y

Oak Ridge, TN 37830

ATTN: H. D. Burch

R. T. Jubin

L. J. Mezga

D. W. Turner
No. of

Copies

2 Sandia Laboratories

P.0. Box 5800

Albuquerque, NM 87185

ATTN: R. W. Lynch

Technical Library

J. R. Berreth

Westinghouse Idaho Nuclear

Co., Inc.

P. 0. Box 4000

Iḍaho Falls, ID 83401

6 E. 1. du Pont de Nemours Company

Savannah River Laboratory

Aiken, SC 29801

ATTN: R. G. Baxter

M. D. Boersma

J. G. Glasscock

J. R. Knight

M. J. Plodinec

C. T. Randall

A. D. Rodgers

Mail Stop 2411

EG\&G Idaho

P.0. Box 1625

Idaho Falls, ID 83415

R. Shaw

Electric Power Research

Institute

$3412 \mathrm{Hill}$ iview Avenue

P.0. Box 10412

Palo Alto, CA 94303

4 West Valley Nuclear Service Company

P.0. Box 191

Hest Valley, NY 14171

ATTN: J. C. Cwynar

J. E. Krauss

S. J. Marchette

J. M. Pope 
No. of

Copies

J. L White, Chairman

Energy Research and Development Authority

Empire State Plaza

Albany, NY 12223

\section{ONSITE}

6 DOE Richland Operations Office

C. E. Collantes

M. J. Furman

R. E. Gerton

A. J. Rizzo

M. W. Shupe

J. J. Sutey

8 Westinghouse Hanford Company

J. M. Henderson

R. E. Lerch

H. E. McGuire

J. L. Scott

D. A. Turner

D. D. Wodrich

R. D. Wojtasek

B. A. Wolfe

58 Pacific Northwest Laboratory

C. R. Allen

M. J. Apted

H. W. Ballard, Jr.

S. 0. Bates (2)

W. F. Bonner

W. M. Bowen (5)

D. J. Bradley

R. A. Brouns (2)

M. J. Budden

L. R. Bunnell (20)

H. C. Burkholder

C. C. Chapman

T. T. Claudson

M. R. EImore
No. of

Copies

T. L. Gilbride

R. W. Goles

W. L. Kuhn

L. T. Lakey

D. E. Larson

J. L. McElroy

R. K. Nakaoka

J. M. Perez, Jr.

M. E. Peterson

H. A. Ross

D. H. Siemens

S. C. Slate

Publishing Coordination (2)

Technical Report Files (5) 
$+$

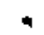

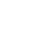

